\title{
Dynamic analysis of pulsed cisplatin identifies effectors of resistance in lung adenocarcinoma
}

Jordan F. Hastings ${ }^{1}$, Alvaro Gonzalez-Rajal ${ }^{1}$, Jeremy Z.R. Han $^{1}$, Rachael A. McCloy ${ }^{1}$, Yolande E.I. O’Donnell ${ }^{1}$, Monica Phimmachanh ${ }^{1}$, Alexander D. Murphy ${ }^{2}$, Adnan Nagrial $^{2}$, Dariush Daneshvar ${ }^{2}$, Venessa Chin ${ }^{1,3,4}$, D. Neil Watkins ${ }^{5,6,7,8}$, Andrew Burgess ${ }^{9,10 \#}$, David R. Croucher ${ }^{1,411 \#}$.

1: The Kinghorn Cancer Centre, Garvan Institute of Medical Research, Sydney, NSW 2010, Australia.

2: Crown Princess Mary Cancer Centre, Westmead and Blacktown Hospitals, Sydney, NSW 2145, Australia.

3: St Vincent's Hospital Sydney, Darlinghurst, NSW 2010, Australia

4: St Vincent's Hospital Clinical School, University of New South Wales, Sydney, NSW 2052,

Australia.

5: Hudson Institute of Medical Research, Clayton, Victoria 3168, Australia.

6: Department of Molecular and Translational Medicine, School of Medicine, Nursing and Health Sciences, Monash University, Clayton, Victoria 3800, Australia.

7: Research Institute in Oncology and Hematology, CancerCare Manitoba, Winnipeg, MB, Canada, R3E-0V9

8: Department of Internal Medicine, Rady Faculty of Health Science, University of Manitoba, Winnipeg, Canada, R3E 0W2

9: ANZAC Research Institute, Concord, NSW 2139, Australia

10: The University of Sydney Concord Clinical School, Faculty of Medicine and Health, Sydney, NSW 2139, Australia

11: School of Medicine, University College Dublin, Belfield, Dublin 4, Ireland.

*Co-first Authors

\# Co-Corresponding Authors

Running Title: Targeting P70S6K overcomes platinum resistance in lung adenocarcinoma.

\section{Keywords:}

\section{Corresponding Authors:}

Dr David Croucher

The Kinghorn Cancer Centre

Garvan Institute of Medical Research

370 Victoria St, Darlinghurst, NSW, 2010

Email: d.croucher@garvan.org.au

Phone: +61 293555820

A/Prof Andrew Burgess

ANZAC Research Institute,

Hospital Road, Concord, NSW, 2139

Email: andrew.burgess@ sydney.edu.au

Phone: +61 297679104

Word Count: 4927 (Introduction, Results and Discussion)

Figures: 7 
Targeting P70S6K overcomes platinum resistance in lung cancer - Hastings et al.

\begin{abstract}
Identification of clinically viable strategies for overcoming resistance to platinum chemotherapy in lung adenocarcinoma has been hampered by inappropriately tailored in vitro assays of drug response. Therefore, using a pulse model that closely recapitulates the in vivo pharmacokinetics of platinum therapy, we profiled cisplatin-induced signalling, DNA damage and apoptotic responses across a panel of lung adenocarcinoma cell lines. By coupling this data with real-time, single cell imaging of cell cycle and apoptosis, we show that TP53 mutation status influenced the mode of cisplatin induced cell cycle arrest, but could not predict cisplatin sensitivity. In contrast, P70S6K-mediated signalling promoted resistance by increasing p53/p63 and p21 expression, reducing double-stranded DNA breaks and apoptosis. Targeting P70S6K sensitised both TP53 wildtype and null lines to cisplatin, but not TP53 mutant lines. In summary, using in vitro assays that mimic in vivo pharmacokinetics identified P70S6K as a robust mediator of cisplatin resistance and highlighted the importance of considering somatic mutation status when designing patient-specific combination therapies.
\end{abstract}


Targeting P70S6K overcomes platinum resistance in lung cancer - Hastings et al.

\section{Introduction}

Lung adenocarcinoma is the most common form of lung cancer, the leading cause of cancer-related death worldwide. Lung adenocarcinoma is typically diagnosed late, meaning that most patients require systemic chemotherapy (Chen et al., 2014). Platinum-based chemotherapy is likely to remain an important treatment modality for these patients due to the emergence of resistance to targeted therapies in EGFR, ALK or ROS mutant tumours (Lindeman et al., 2018), and the fact that most patients do not respond to single agent immunotherapy (Doroshow et al., 2019, Kim et al., 2019).

Despite the use of platinum-based chemotherapy in lung adenocarcinoma for over four decades, response rates remain below 30\% due to the prevalence of innate resistance (Bonanno et al., 2014, Pilkington et al., 2015). In addition, dose-related nephrotoxicity remains a challenge in many patients (Pabla \& Dong, 2008). Strategies to improve platinum efficacy could therefore significantly improve outcomes for lung adenocarcinoma patients. However, unravelling platinum resistance in lung adenocarcinoma has proven challenging, as over 147 mechanisms of resistance have been proposed (Stewart, 2007), yet there remains a lack of viable clinical options to improve response rates.

From an experimental viewpoint, discordance between the in vivo pharmacokinetics of platinum chemotherapies and their use within in vitro assays has likely contributed to the identification of putative resistance mechanisms and drug targets that have not ultimately translated to the clinic. We have previously shown that predictive models of drug-induced apoptotic signalling dynamics can be used to stratify cancer patients (Fey et al., 2015). To apply a similar concept to platinum resistance, we first considered that traditional in vitro methods have involved measures of drug response in cancer cells cultured in the continuous presence of high-dose chemotherapy over several days. This contrasts with pharmacokinetic studies in humans and rodents demonstrating that both cisplatin and carboplatin are rapidly cleared from the circulation, and the tumour, within 2-3 hours following administration (Andersson et al., 1996, Johansen et al., 2002). Therefore, in this study we have utilised a cisplatin pulse model which more closely recapitulates these physiological pharmacokinetics, aiming to maintain the fidelity of the apoptotic mechanism mediated by cisplatin in vivo.

We now present an in-depth analysis of the dynamic signalling response to a pulse of platinum chemotherapy, describing the relationship between a number of key signalling nodes, the DNA damage response and platinum sensitivity. Importantly, we also propose a therapeutic strategy targeting P70S6K using the dual PI3K/mTOR inhibitor dactolisib, with the potential to improve the efficacy of current platinum based treatment regimens. 
Targeting P70S6K overcomes platinum resistance in lung cancer - Hastings et al.

\section{Results}

\section{Continuous versus pulsed cisplatin treatment}

In order to directly compare the response of lung adenocarcinoma cells to the continuous presence of cisplatin, or a pulse of cisplatin that mimics in vivo pharmacokinetics $(2 \mathrm{~h}, 5 \mu \mathrm{g} / \mathrm{mL}$ ) (Figure 1A), we monitored the growth and apoptosis of the innately resistant A549 lung adenocarcinoma cell line (Marini et al., 2018) by live cell imaging under both conditions (Figure 1B). This analysis demonstrated that while continuous exposure to cisplatin resulted in decreased cell number and increased apoptosis over $72 \mathrm{~h}$, a pulse of cisplatin only reduced the rate of cell proliferation and did not induce apoptosis.

To further examine the differences between these two models, we used multiplexed, bead-based protein analysis to investigate the DNA damage, apoptotic and signalling response for key pathway components previously implicated in the response to continuous cisplatin exposure (I.e. p38, ERK, JNK and MCL-1) (Marini et al., 2018, Stewart, 2007) (Figure 1C, Supplementary Figure 1). As might be expected, the continuous exposure model resulted in a significantly elevated and sustained DNA damage response when compared to the pulse model, particularly for the phosphorylation of Chk2 (Ser345), p53 (Ser15 and Ser46), pH2A.X (Ser139 - $\gamma$ H2A.X) and expression of p21 and MDM2. This heightened DNA damage response during the continuous exposure to cisplatin was also reflected in the increased activation of Caspase 3, which was completely absent for the pulse model. Furthermore, while p38 and ERK activation were significantly increased in cells continuously exposed to cisplatin, the expression of MCL-1 and detection of MCL-1/Bak dimers only significantly increased in cells treated with a pulse of cisplatin. This finding demonstrates that not only does the continuous exposure model result in a DNA damage and apoptotic response that is incongruent with that observed following a pulse of cisplatin, the dynamics of key signalling pathways are fundamentally different between these two treatment models. Taken together, this data demonstrates that previous mechanisms of platinum resistance established using a continuous exposure model may be based on artefacts arising from non-physiological levels of drug exposure.

\section{Response to cisplatin is not associated with either TP53 status or drug-efflux}

To investigate potential mechanisms of platinum resistance using a model consistent with the physiological pharmacokinetics of platinum therapy, we applied this cisplatin pulse model to a panel of six lung adenocarcinoma cell lines with distinct TP53 mutation backgrounds (two wildtype lines, two mutant TP53 lines and two TP53 null) and measured the apoptotic response at $72 \mathrm{~h}$ (Figure 1D). Based upon this model we observed a range of sensitivity to cisplatin, from the most resistant A549 line ( $\sim 3 \%$ apoptosis) to the most responsive NCI-H1299 line ( $\sim 32 \%$ apoptosis). However, these cell 
Targeting P70S6K overcomes platinum resistance in lung cancer - Hastings et al.

lines could not be stratified simply according to their TP53 mutation status, or other frequently observed genetic alterations (Supplementary Table 1).

As the action of drug-efflux pumps is another commonly proposed mechanism of resistance to platinum therapy (Hoffmann \& Lambert, 2014), we performed fluorescence microscopy with an antibody towards cisplatin-induced DNA adducts at multiple time-points following a $2 \mathrm{~h}$ cisplatin pulse (Figure 1D). This analysis demonstrated that within this model, all six cell lines displayed significant nuclear localised cisplatin-DNA adducts following a $2 \mathrm{~h}$ pulse (Figure 1E, Supplementary Figure 2), suggesting that drug efflux is not associated with variations in the apoptotic response to a pulse of cisplatin in these lines. Furthermore, these cisplatin-DNA adducts progressively resolved over a $72 \mathrm{~h}$ period in all cell lines (Figure 1C), confirming that pathways responsible for facilitating the removal of cisplatin adducts are also functional across this panel.

\section{Multi-dimensional analysis of cisplatin-induced signalling dynamics}

To gain an understanding of the wider signalling networks associated with resistance to platinum therapy, we utilised multiplexed, magnetic bead based assays to profile the signalling and DNA damage response at multiple time points following a $2 \mathrm{~h}$ pulse of cisplatin, across all six cell lines (Figure 1F). For this analysis, we tracked the dynamics of 47 different protein analytes (Supplementary Table 2) over a 72 hour period, focusing on elements of signalling network structures that we recently implicated in platinum chemoresistance (Marini et al., 2018), including the MAPK, $\mathrm{PI} 3 \mathrm{~K} / \mathrm{mTOR}, \mathrm{NF}-\kappa \mathrm{B}$ and TGF $\beta$ pathways, as well as a number of key apoptotic mediators and DNA damage response proteins (Figure 1G).

From this dataset, a clear correlation can be seen between the TP53 mutation status of each cell line and the dynamics of the p53 pathway (Supplementary Figure 3), which validates the fidelity of the multiplexed analysis platform for this form of analysis. In line with the detection of cisplatin-DNA adducts (Figure 1E), Chk1 (Ser345) phosphorylation increased rapidly in all lines following the $2 \mathrm{~h}$ pulse, followed by a slower wave of Chk2 (Thr68) phosphorylation in all lines except SW1573. Within both the TP53 wildtype cell lines (A549 and SW-1573) this was followed by phosphorylation of p53 (Ser15 and Ser46), the accumulation of total p53 and increased expression of the p53 transcriptional targets MDM2 and p21. In the TP53 mutant cell lines (NCI-H1573 and NCI-H1975) p53 phosphorylation still occurred, however in line with their loss of DNA binding capability, this did not result in increased expression of MDM2 or p21. As would be expected for the TP53 null lines (NCI-H358 and NCI-H1299), p53 is absent and therefore not detected in either the total or phosphorylated form. Interestingly though, there was a significant increase in p21 and MDM2 expression in the NCI-H358 line in the absence of p53 expression. 
Targeting P70S6K overcomes platinum resistance in lung cancer - Hastings et al.

As we had already determined that TP53 status alone was not sufficient to explain resistance to cisplatin (Figure 1D), we further analysed the whole dataset by performing a principal component analysis (PCA) (Figure 2). This analysis created a visual representation of the dynamic association between key signalling nodes and the response to cisplatin across the entire cell line panel. Using this multidimensional analysis, we were able to capture $\sim 70 \%$ of variance in the dataset within the first 4 principal components (Supplementary Figure 4A). Unsurprisingly, plotting the first two principal components against each other (Figure $2 \mathrm{~A}$ ) resulted in separation of the cell lines primarily according to their TP53 status. As might be expected, within these components the TP53 wild-type A549 and SW-1573 lines associated with higher p21 and MDM2 expression, while the TP53 mutant lines separated from the TP53 null lines mostly on the basis of higher p53 expression and phosphorylation levels (Figure 2A,B,C). However, plotting the third and fourth principal components (Figure 2D,E) created a clear delineation between the three most resistant cell lines (A549, NCI-H358 and NCIH1573), which cluster towards the left hand side of component 3 (x-axis), and the three most sensitive lines (SW-1573, NCI-1975 and NCI-H1299) which move progressively along component 3 over the $72 \mathrm{~h}$ timeframe.

\section{Validation of model-based observations}

As platinum chemotherapies work by forming covalent DNA adducts, which distort the DNA helix and block replication, the progressive accumulation of single stranded and double stranded breaks is thought to induce apoptosis (Jamieson \& Lippard, 1999). This is in line with the movement of cisplatin sensitive cell lines along component 3 (x-axis) towards higher levels of $\gamma \mathrm{H} 2 \mathrm{~A} . \mathrm{X}$ $\left(\mathrm{H} 2 \mathrm{~A} . \mathrm{X}^{\mathrm{S} 139}\right.$ ), cleaved caspase 3 and a stress associated MAPK signalling axis (pATF2, pJNK, pc-Jun) (Figure 2D,E). The association between this signalling state and increased sensitivity to cisplatin can also be clearly observed by overlaying an orthogonal readout of the apoptotic response onto this PCA plot (Figure 3A), generated using live cell imaging to measure caspase activity as an indicator of cell death for $72 \mathrm{~h}$ following the cisplatin pulse treatment.

Using this approach, we now created a visual representation that both reflects the variance within the original dataset and demonstrates the key signalling nodes that are associated with differing degrees of platinum-induced apoptosis. While increasing levels of apoptosis are observed over time in the three sensitive cell lines (SW-1573, NCI-1975 and NCI-H1299), the three resistant cell lines display significantly lower levels of apoptosis (Supplementary Figure 4B) and do not move along component 3 towards the region of DNA damage and apoptosis. Instead the NCI-H358 and NCI-1573 lines remain towards the left hand side of component 3 , in a region characterised by higher phosphorylation of the mTOR pathway component P70S6K (Thr389), the MAPK components MEK1 (Ser217/221)

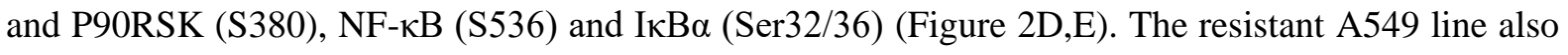
remains shifted towards the left of component 3, although also moves up component 4 towards a 
Targeting P70S6K overcomes platinum resistance in lung cancer - Hastings et al.

region with higher expression of TGFßRII, cleaved caspase 9, pAkt (Ser473) and pSTAT3 (Ser727) (Figure 2D,E). The association of elevated pMEK (Ser217/221), pNF-kB (S536), pSTAT3 (Ser727) and pP70S6K (Thr389) within these resistant cell lines was also further confirmed by western blotting of independent samples (Figure 2C).

The clear separation of resistant and sensitive cell lines within this multi-dimensional analysis suggests an antagonistic relationship between apoptosis promoted through the progressive accumulation of DNA-damage following a cisplatin pulse, and elevated mTOR, MAPK, Akt, STAT or NF- $\mathrm{\kappa B}$ signalling events. However, as a statistical process, relationships derived from a principal component analysis are purely correlative in nature and require a further degree of validation before any causative conclusions may be drawn. We therefore sought to identify effectors of platinum resistance by including specific inhibitors of these signalling pathway components during and after the $2 \mathrm{~h}$ cisplatin pulse, followed by a measurement of apoptosis at $72 \mathrm{~h}$ (Figure 3B). Using the resistant A549 (Figure 3C) and NCI-H358 (Figure 3D) cell lines we observed that specific inhibitors of Akt (MK2206), STAT3 (S3I-201), MEK (UO126) or NF- אB (SC-75741) did not significantly increase apoptosis in either cell line, suggesting that while elevated activity of these signalling proteins may be present in one or both of these resistant lines (Figure 2C), they are not causally associated with resistance to cisplatin. Instead, under these conditions, only the inhibition of P70S6K with the dual PI3K/mTOR inhibitor dactolisib resulted in a significant increase in cisplatin-induced apoptosis in both cell lines. P70S6K is a serine/threonine-specific protein kinase known to require phosphorylation by both PI3K and mTOR for activation (Sunami et al., 2010) (Moser et al., 1997). While dactolisib will result in the inhibition of a number of substrates downstream of both PI3K and mTOR, the lack of sensitisation by an Akt inhibitor (MK2206) suggests a specific role for P70S6K in mediating resistance to cisplatin.

Taking the opposite approach, elevated levels of JNK pathway activity (pJNK, pc-Jun) were also observed following cisplatin treatment within the SW-1573 line (Figure 2C,D,E). However, the inclusion of a JNK inhibitor (JNK inhibitor VIII) did not prevent cisplatin induced apoptosis in this cell line (Supplementary Figure 4C), suggesting that JNK activity was not promoting apoptosis in this context.

\section{P70S6K promotes platinum resistance in lung adenocarcinoma}

Comparing the relative expression levels of phosphorylated P70S6K across our stratified panel of cell lines, higher expression was observed in the resistant NCI-H358 and NCI-H1573 lines (Figure 2C). This expression pattern was also mirrored by the levels of total P70S6K (Figure 2C), which seems to be primarily driving the observed levels of P70S6K phosphorylation. Interestingly, the resistant A549 line did not have elevated P70S6K expression or phosphorylation, although as reflected in the PCA plot (Figure 2E) this cell line did have high expression of the P70S6K substrate, Ribosomal Protein 
Targeting P70S6K overcomes platinum resistance in lung cancer - Hastings et al.

S6, leading to a level of phosphorylation equivalent to that observed in the resistant NCI-H358 line (Figure 2C).

Utilising the highest expressing (NCI-H358) and lowest expressing (NCI-H1299) lines, which are also both TP53 null, we observed that cisplatin treatment resulted in greater caspase 3 cleavage and $\gamma$ H2A.X expression in the sensitive NCI-H1299 line (Figure 3E), which is in line with the multiplexed signalling analysis (Figure 1G). Crucially, treatment of the resistant NCI-H358 line with dactolisib during and after the cisplatin pulse increased both caspase 3 cleavage and $\gamma \mathrm{H} 2 \mathrm{~A}$.X expression to that observed in the sensitive NCI-H1299 line. Conceptually, this now mimics the movement of the resistant NCI-H358 line along component 3 of our PCA analysis, towards the region of DNA damage and apoptosis characterised by the sensitive cell lines (Figure 2, 3A). This finding demonstrates that while this form of multi-dimensional analysis of signalling networks creates a set of correlative relationships, this data can also be utilised to investigate causal effectors of downstream cellular behaviour.

As mentioned above, dactolisib can efficiently inhibit the phosphorylation of P70S6K, but will also result in the inhibition of a number of other potential PI3K/mTOR substrates. To confirm that P70S6K is a key downstream component mediating platinum resistance in this context, we knocked down P70S6K using siRNA in the NCI-H358 line, prior to proceeding with a cisplatin pulse (Figure $3 \mathrm{~F})$. Under these conditions, cisplatin treatment resulted in significantly higher caspase 3 cleavage and $\gamma$ H2A.X expression in the P70S6K knockdown cells (Figure 3G). Additionally, P70S6K knockdown also significantly increased cisplatin-induced apoptosis in the NCI-H358 cells, to the same extent as that observed with dactolisib treatment (Figure 3H).

To further validate this combination therapy approach in vivo and validate the findings of our pulse model, we treated mice bearing NCI-H358 xenografts with either carboplatin, dactolisib, or a combination of both (Figure 3I). For this model, dactolisib $(45 \mathrm{mg} / \mathrm{kg}$ ) was delivered by oral gavage, prior to a one-off intraperitoneal injection of carboplatin $(60 \mathrm{mg} / \mathrm{kg})$, and throughout the course of the experiment. Under these conditions, carboplatin had no significant effect upon tumour growth, while dactolisib had a moderate effect as a single agent that was only significant at days 14 and 17 . However the combination of carboplatin and dactolisib completely halted tumour growth, even up to 28 days following the single pulse of carboplatin treatment. Furthermore, an analysis of tumour sections revealed that the carboplatin and dactolisib treated xenografts were not only smaller in size, but also had significantly larger regions of necrosis (Figure 3J).

These findings demonstrate that elevated P70S6K activity can specifically mediate resistance to platinum therapy in lung adenocarcinoma, which can be effectively targeted with the dual $\mathrm{PI} 3 \mathrm{~K} / \mathrm{mTOR}$ inhibitor dactolisib. Importantly, elevated P70S6K activity is frequently observed in 
Targeting P70S6K overcomes platinum resistance in lung cancer - Hastings et al.

several cancer subtypes, including lung cancer (Chen et al., 2017), and its overexpression is commonly associated with aggressive malignant phenotypes and poor overall prognoses (Ip \& Wong, 2012). Indeed, an analysis of TCGA data using cBioPortal (Cerami et al., 2012, Gao et al., 2013) reveals that RPS6KB1 and RPS6KB2, the two isoforms of P70S6K, are amplified or over-expressed in $20 \%$ and $11 \%$ of lung adenocarcinoma cases, respectively (Figure 4A). Importantly, while TP53 mutations or deletions also occur within $47 \%$ of lung adenocarcinomas, RPS6KB1 and RPS6KB2 amplification/over-expression occur on the background of either wildtype or mutant TP53.

Further analysis with KM plotter (Gyorffy et al., 2013) demonstrated that the elevated mRNA expression of both isoforms was also significantly associated with poor overall survival of lung adenocarcinoma patients (Figure 4B). We therefore investigated the association with survival and response to chemotherapy by performing IHC for total P70S6K in a cohort of 52 lung adenocarcinoma patients that all received a neoadjuvant chemotherapy regimen containing platinumbased chemotherapy (Figure 4C, Supplementary Table 3). In this cohort, high expression of P70S6K was significantly associated with poor overall survival (Figure 4D), while there was a non-significant trend towards higher P70S6K expression in patients with progressive disease (Figure 4E) and a later disease stage (Figure 4F). In 8 patients with matched diagnosis and relapse samples, the levels of P70S6K expression were also significantly increased upon relapse (Figure 4G), further highlighting the functional role of P70S6K in the cellular response to platinum therapy.

\section{P70S6K promotes cell cycle arrest in response to cisplatin}

As P70S6K has a known role in cell cycle progression (Lane et al., 1993), we performed live cell imaging of the FUCCI two-colour sensor of cell cycle progression (Sakaue-Sawano et al., 2008) across the resistant A549, NCI-H1573 and NCI-H358 cell lines. This approach allowed us to track the cell cycle progression and fate of individual cells for $72 \mathrm{~h}$ following treatment with a $2 \mathrm{~h}$ pulse of cisplatin (Figure 5A). In this assay, treatment with a single pulse of cisplatin caused several notable cell cycle responses. First, A549 (TP53 wildtype) and NCI-H358 (TP53 null) cells were significantly more likely to remain arrested in $\mathrm{G} 1$, both before (G1 arrest before mitosis; $A B M)$ and after undergoing mitosis (G1 arrest after mitosis; AAM) (Figure 5B,C). In contrast, NCI-H1573 cells did not show any significant increase in G1 transit time, as may be expected from a TP53 mutant cell line.

For all cell lines, cisplatin pulsing resulted in a significant increase in S/G2 transit time (Figure 5B,C). Notably, the NCI-H1573 (TP53 mutant) and NCI-H358 (TP53 null) cells delayed for more time in G2 (G2 arrest; mean 2443 min and 2555 min respectively) compared to A549 cells (mean 1426 min), after which the mutant and null cells often entered a prolonged aberrant mitosis (Supplementary Figure 5), resulting in a small increase in cells dying during mitosis or in the following G1/S phase (Figure 5C, death after mitosis; DAM). In contrast, A549 cells rarely entered into mitosis, instead many of these S/G2 arrested cells turned from green (S/G2) back to red (G1) without undergoing 
Targeting P70S6K overcomes platinum resistance in lung cancer - Hastings et al.

mitosis (G2-exit) (Supplementary Figure 5). A similar G2-exit, senescence state has been reported to be dependent on p21 (Gire \& Dulic, 2015) and likely provides TP53 wildtype cells protection from death by preventing progression through an aberrant mitosis.

Treatment of all cell lines with dactolisib as a single agent also caused a significant increase in G1 arrest both before (G1 ABM) and after mitosis (G1 AAM), irrespective of TP53 status (Figure 5B,C). Consequently, for all cell lines, dactolisib treatment of cells within early G1 phase during the cisplatin pulse resulted in many cells remaining arrested and viable in G1 (G1 ABM), highlighting the importance of DNA replication for inducing cisplatin induced toxicity and killing. However, for the TP53 wildtype and null cells that were in late G1 or S phase at the time of cisplatin pulsing, dactolisib treatment significantly reduced S/G2 transit time (Figure 5B) and greatly increased the number of cells that underwent apoptosis before mitosis (Death before mitosis; DBM) (Figure 5C,D). Notably, dactolisib treatment did not prevent cisplatin treated cells from entering into an aberrant mitosis, but did significantly increase the duration of mitotic arrest, independent of TP53 status (Figure 5B), which correlated with an increase in death during or after mitosis (DAM) in TP53 wildtype and null, but not mutant cells (Figure 5C,D). Surprisingly, dactolisib treatment did not result in any sensitisation of TP53 mutant H1573 cells to cisplatin (Figure 5D), which also corresponded with a failure of dactolisib to significantly reduce S/G2 phase transit time (Figure 5B).

In summary, combination therapy with dactolisib sensitised actively cycling cells to cisplatin through distinct mechanisms dependent on TP53 status. In the TP53 wildtype A549 cells it induced premitotic cell death and prevented cells from undergoing a protective G2-exit, which is likely partially dependent on the p53-p21 axis. Similarly, in the TP53 null line, dactolisib promoted both pre-mitotic cell death and the entry of cells into a prolonged deleterious aberrant mitosis, the latter likely due to a weakened p53-dependent G2 checkpoint(Engeland, 2018). While in TP53 mutant H1573 cells, there was no significant sensitisation due to a sustained S/G2 arrest in the presence of dactolisib.

\section{Response to dactolisib is dependent upon TP53 status}

A notable observation arising from this cell cycle analysis was the ability of dactolisib to increase apoptosis by preventing an unexpected cell cycle arrest in the TP53 null NCI-H358 cell line. Interestingly, this association between cell cycle arrest and cisplatin resistance can also be observed from the original analysis of signalling dynamics (Figure 1G, Supplementary Figure 3). While both the NCI-H1299 and NCI-H358 cell lines are TP53 null, there was an increased expression of p21 following cisplatin treatment in the resistant NCI-H358 line, but not the sensitive NCI-H1299 line. Importantly, the increased p21 expression by NCI-H358 cells was also observed by western blotting of independent samples and was efficiently inhibited by both treatment with dactolisib (Figure 6A,B) and the specific knockdown of P70S6K with siRNA (Figure 6C). Taken together, this data suggests 
Targeting P70S6K overcomes platinum resistance in lung cancer - Hastings et al.

that P70S6K activity is necessary for promoting p21 expression in order to maintain cell cycle arrest following cisplatin treatment. However, in the absence of p53, we observed that this can be mediated by the related transcription factor p63, which is elevated in the NCI-H358 line following treatment with cisplatin, and also inhibited by the addition of dactolisib (Figure 6A,B) or treatment with P70S6K siRNA (Figure 6C).

Given the potential role for p21 in mediating resistance to cisplatin in the NCI-H358 line, we investigated whether sensitisation by dactolisib would be generalizable across the original panel of 6 lung adenocarcinoma cell lines with differing TP53 status. In accordance with this hypothesis, and in line with the FUCCI single-cell imaging (Figure 5A), both the TP53 wildtype cell lines were significantly sensitised to cisplatin by the addition dactolisib, as was the resistant TP53 null line, NCIH358 (Figure 2D, 2H, 6D). The sensitive TP53 null line, NCI-H1299, was not further sensitised and appeared to already be at the upper limit of apoptosis within this model. Also, in line with the FUCCI analysis, dactolisib was not able to increase cisplatin-induced apoptosis in the TP53 mutant line NCIH1573, whilst it significantly antagonised cisplatin-induced apoptosis in the TP53 mutant NCI-H1975 line.

Lending further support to the key role of p21 in mediating cell cycle arrest, and thereby preventing DNA damage induced apoptosis, the addition of dactolisib inhibited p53 and p21 accumulation in the TP53 wildtype A549 cell line, resulting in elevated $\gamma \mathrm{H} 2 \mathrm{~A} . \mathrm{X}$ expression and caspase 3 cleavage following cisplatin treatment (Figure 6E). However, in the TP53 mutant NCI-H1573 line, which was not sensitised by dactolisib, p21 expression was not significantly elevated following cisplatin treatment, meaning that $\gamma \mathrm{H} 2 \mathrm{~A} . \mathrm{X}$ expression and caspase 3 cleavage were already elevated and could not be inhibited by dactolisib (Figure 7).

To further validate this link between sensitisation by dactolisib and TP53 mutation status, we took another panel of 8 lung adenocarcinoma cell lines (Supplementary Table 4) and correlated their relative expression of phosphorylated P70S6K (Figure 6F) to their apoptotic response to cisplatin (Figure 6G). This secondary analysis revealed a general trend towards higher levels of phosphorylated P70S6K and decreased apoptosis in response to cisplatin across the whole panel. However, the strength of this correlation was greatly increased when considering the TP53 status of the lines, with a strong correlation observed for wildtype TP53 lines $\left(r^{2}=0.6092\right)$ but no correlation for TP53 mutant lines $\left(r^{2}=0.1764\right)$. In agreement with our finding that elevated P70S6K activity promotes resistance in a TP53 dependent manner, combination therapy with cisplatin and dactolisib significantly sensitised the high pP70S6K/TP53 wildtype NCI-H292 cell line, but not the high pP70S6K/TP53 mutant NCI-H2009 line. Therefore, this data demonstrates that P70S6K promotes p21-dependent cell cycle arrest following cisplatin treatment, presumably through enhanced translation of $\mathrm{p} 53 / \mathrm{p} 21$ in TP53 wildtype cell lines and p63/p21 in TP53 null lines (Figure 7). However, in the presence of 
Targeting P70S6K overcomes platinum resistance in lung cancer - Hastings et al.

mutant p53, P70S6K is not able to influence this DNA damage induced signalling axis and is therefore not associated with sensitivity to cisplatin.

\section{Discussion}

A number of studies have been performed investigating the potential mechanisms of resistance to platinum-based chemotherapies (Stewart, 2007), although this has yet to result in the identification of clinically successful combination therapies for lung adenocarcinoma. One potential explanation for the high number of in vitro findings that have not translated to the clinic is the use of experimental techniques that do not replicate the in vivo pharmacokinetics of platinum therapies (Shen et al., 2012). To date, most in vitro approaches have involved continuously culturing cell lines in the presence of high doses of platinum chemotherapy for multiple days, potentially allowing for more extensive DNA damage and off-target effects that would not be seen in vivo. Here we have utilised a pulse model that more accurately models both the concentration and timing of cisplatin that would be observed clinically. This is an important consideration, as platinum therapies are known to act via the formation of DNA adducts, although they are also capable of bonding with proteins and RNA (Jamieson \& Lippard, 1999). It is likely that the continuous culturing of cells in the presence of high doses of these drugs in vitro would result in the accumulation of numerous off-target adducts and the activation of a stress response incongruent with the actual in vivo apoptotic mechanism. Indeed, this effect may be apparent in Figure 1C, where p38 activity is induced by the continuous exposure model, but not by the pulse model. A number of previous studies have implicated the activity of p38 in mediating resistance to cisplatin (Galan-Moya et al., 2011, Hernandez Losa et al., 2003, Pereira et al., 2013, Sarin et al., 2018), however we did not observe highly elevated p38 signalling in any cell line following the cisplatin pulse (Figure 1F), nor a correlation between p38 activity and the apoptotic response (Figure 2).

Instead, through the use of this pulse model, and by overlaying real-time apoptosis data onto a multivariate signalling analysis across a panel of lung adenocarcinoma lines, we have now identified elevated P70S6K activity as an effector of inherent platinum chemoresistance. High levels of P70S6K expression have previously been associated with aggressive tumour behaviour in lung cancer (Chen et al., 2017), as well as other cancer types such as breast (Holz, 2012), colorectal (Nozawa et al., 2007) and liver (Sahin et al., 2004) cancers. This is also supported by our analysis of P70S6K expression patient samples (Figure 4), where high mRNA and protein levels were both associated with poor overall survival, and P70S6K protein expression was significantly elevated in relapsed tumours. Importantly, we also propose that combination therapy with the dual PI3K/mTOR inhibitor dactolisib can sensitise lung adenocarcinomas to platinum chemotherapy, although only in the context TP53 WT or TP53 null tumours. This detailed mechanistic understanding is especially important given that P70S6K amplification can occur on a background of either mutant or wildtype TP53 (Figure 4A). 
Targeting P70S6K overcomes platinum resistance in lung cancer - Hastings et al.

Functionally, dactolisib will result in the inhibition of a number of substrates downstream of PI3K and mTOR. However, as the specific knockdown of P70S6K with siRNA recapitulated the effects of dactolisib on p63, p21, $\gamma \mathrm{H} 2 \mathrm{~A} . \mathrm{X}$, cleaved caspase 3 and apoptosis, it is likely that the elevated expression and activity of P70S6K in resistant lung adenocarcinoma cells is the functional target of dactolisib and a causal effector of platinum resistance in these cells. Further supporting this central role of P70S6K, previous research has demonstrated that P70S6K can regulate cell cycle progression via the enhanced translation of p21 mRNA (Guegan et al., 2014), although our data also suggest that P70S6K may also play a role in the enhanced expression of both p53 and p63 in this context.

The combination of cisplatin and dactolisib has also previously been proposed for osteosarcoma (Huang et al., 2018), head and neck squamous cell carcinoma (Hsu et al., 2018) and bladder cancer (Moon du et al., 2014). However, our finding that this combination therapy is effective in TP53 WT and null, but not TP53 mutant tumours, has significant implications for the clinical application of these drugs and the design of potential clinical trials. The failure of many clinical trials is frequently attributed to the lack of suitable biomarkers to stratify the patient cohort (Hay et al., 2014), highlighting the value of our approach that is capable of dissecting the mechanism of variable drug response across differing genetic backgrounds. The inability of dactolisib to regulate p21 expression in TP53 mutant tumour cells following cisplatin treatment likely underlies the inability of dactolisib to sensitise these cells to cisplatin. Therefore, within the context of a potential clinical trial for this drug combination, the TP53 mutation status of each patient tumour would be a central consideration for identification of the most effective treatment strategy and an understanding of individual patient response. However, this finding is also widely applicable to the understanding of how cancer-related signalling networks govern drug response and chemoresistance, and how a thorough characterisation of these dynamics will be necessary for the proper design and implementation of any consistently effective, patient-specific therapy. 
Targeting P70S6K overcomes platinum resistance in lung cancer - Hastings et al.

\section{Materials and Methods}

\section{Antibodies, Plasmids, and Reagents}

The cisplatin modified DNA (ab103261) and $\gamma \mathrm{H} 2 \mathrm{~A} . \mathrm{X}$ (ab26350) antibodies were from Abcam (Cambridge, USA). The phospho-STAT3 S727 (\#9134), phospho-Akt S473 (\#9271), phospho-NF-kB S536 (\#3033), pERK T202/Y204 (\#9101), pATF2 T71 (\#5112), (P70S6K (\#2708), phospho-P70S6K T389 (\#9205), p21 (\#2947), cleaved caspase 3 (\#9661) and cleaved caspase 7 (\#9491) antibodies were from Cell Signaling (MA, United States). The $\gamma \mathrm{H} 2 \mathrm{~A} . \mathrm{X}$ (S139) antibody (AB26350) was from Abcam (MA, USA). The p53 antibody (sc-126) was from Santa Cruz Biotechnology (TX, USA). The p63 antibody (NB100-691) was from Novus Biologicals (CO, USA). The actin monoclonal antibody (AC15) was from Sigma-Aldrich (MO, United States). The SignalSilence p70/85 S6 Kinase siRNA was from Cell Signaling (MA, United States). The plasmids for FUCCI live cell imaging, mVenushGeminin(1/110) and mCherry-hCdt1(30/120), were a kind gift from Dr Atsushi Miyawaki (Riken, Japan). Dactolisib (NZP-BEZ235), MK2206, S3I-201, UO126 and SC75741 were all from Selleck Chem (MA, USA).

\section{Cell lines}

All lung adenocarcinoma cell lines have been previously described (Marini et al., 2018). The lines were cultured in Advanced RPMI (serial no) containing 1\% FCS and 1\% GlutaMAX (serial no) under standard tissue culture conditions $(5 \% \mathrm{CO} 2,20 \% \mathrm{O} 2)$. All cell lines were authenticated by short tandem repeat polymorphism, single-nucleotide polymorphism, and fingerprint analyses, passaged for less than 6 months.

Stable cell lines expressing the FUCCI biosensor were generated as previously described (SakaueSawano et al., 2008) using mVenus-hGeminin(1/110) and mCherry-hCdt1(30/120) probes. Briefly, cells were first transduced with mVenus-hGeminin(1/110) lentiviral particles. Cells were FACS sorted based upon Venus fluorescence, and the resulting cell population transduced again with mCherry-hCdt1(30/120) lentiviral particles. mCherry positive cells were FACS sorted, resulting in a double positive population used for live cell imaging.

\section{Flow cytometry}

Samples for flow cytometry were fixed in $-20^{\circ} \mathrm{C}$ ethanol overnight, and then resuspended in a DNA staining solution containing $10 \mathrm{mg} / \mathrm{mL}$ RNaseA and $1 \mathrm{mg} / \mathrm{mL}$ propidium iodide for $30 \mathrm{~min}$ before analysis. Flow cytometry was performed using BD FACS Canto II system.

\section{Confocal Microscopy}


Targeting P70S6K overcomes platinum resistance in lung cancer - Hastings et al.

For the visualisation of cisplatin-DNA adducts following treatment with a pulse of cisplatin $(5 \mu \mathrm{g} / \mathrm{mL}$, 2 h), cells were grown on Histogrip (Life Technologies) coated glass coverslips. Prior to fixation, cells were treated with $1 \%$ Triton X-100 for $1 \mathrm{~min}$, fixed with ice-cold 100\% Methanol and stored overnight at $-20^{\circ} \mathrm{C}$. The cells were then permeabilized with $0.5 \%$ Triton X-100 for $10 \mathrm{~min}$, washed twice with PBS and incubated for 30 min with $2 \mathrm{M} \mathrm{HCl}$ to denature the DNA. Cells were washed again and incubated in $1 \% \mathrm{H}_{2} \mathrm{O}_{2}$ to quench the endogenous peroxidases, before blocking for $30 \mathrm{~min}$ and incubated with primary antibody (1:500) overnight at $4 \mathrm{C}$ in blocking solution. The following day, cells were incubated with Secondary-Biotinylated Ab at RT, before incubating them with ABC solution (Vectastain elite ABC HRP kit, Vector Laboratories). Cells were later incubated with TSA solution (TSA plus Cyanine 3 System, PerkinElmer). DNA was stained with H33342 and images collected using a Leica DMI5500 (40x magnification). Images were quantified using Fiji Software. Briefly, color images were split into separate channels. H33342 channel was used to identify the nucleus and generate a mask that was placed on top of the CisPt-DNA channel to quantify the signal coming from the nuclear area. Cytoplasmic area was manually identified in each cell and signal quantified. Background signal was obtained and subtracted from the nuclear and cytoplasm signal. From this data, a nuclear/cytoplasmic ratio was obtained for between 100 and 200 cells at each time point.

\section{MAGPIX multiplex assays}

Multiplex analysis was performed using a Bio-Plex MAGPIX system (\#171015044) and Bio-Plex Pro-Wash Station (Biorad). All cell lysates were prepared using standard cell lysis buffer (50mM Tris $\mathrm{HCl} \mathrm{pH} 7.4,150 \mathrm{mM} \mathrm{NaCl}, 1 \mathrm{mM}$ EDTA, $1 \%$ (v/v) TritonX-100) supplemented with protease and phosphatase inhibitors. Lysates were analysed on all kits, according to manufacturer's instructions. Data was generated using Bio-Plex Manager MP and analysed on the Bio-Plex Manager 6.1 software.

Lysates were analysed using the Milliplex map DNA Damage/Genotoxicity Magnetic Bead Panel (7plex), Milliplex map Early Apoptosis Magnetic Bead (7-plex), Milliplex map TGF $\beta$ Signalling Pathway Magnetic Bead kit (6-plex), Bio-Plex Pro Cell Signalling Akt Panel (8-plex), Bio-Plex Pro Cell Signalling MAPK Panel (9-plex), Bio-Plex Pro RBM Apoptosis Panel 2 and Bio-Plex Pro RBM

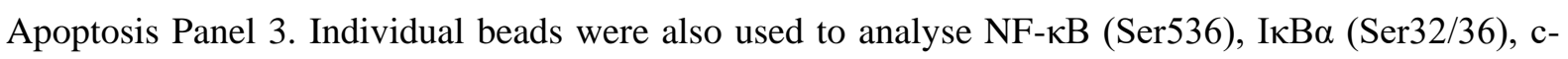
Jun (Ser63), total P53 and cleaved PARP (Biorad). The data was normalized to the median value at the $0 \mathrm{~h}$ time point for each analyte and a log transformation was conducted on the resulting dataset. The principal component analysis was performed using MATLAB and Statistics Toolbox Release 2019a (The Mathworks, Inc., Natick, Massachusetts, United States of America)

\section{Live-cell imaging of apoptosis}


Targeting P70S6K overcomes platinum resistance in lung cancer - Hastings et al.

Live-cell imaging of apoptosis was performed using an Essen Bioscience IncuCyte ZOOM Live-Cell Analysis System and a Thermo Fisher Scientific HERAcell 240i $\mathrm{CO}_{2}$ Incubator. Cells were seeded into Corning Costar TC-treated 96-Well Plates and imaged over a $72 \mathrm{hr}$ period at $2 \mathrm{hr}$ intervals over 4 fields of view per well. Caspase activation was visualised using $1 \mu \mathrm{M}$ NucView 488 Caspase-3 Enzyme Substrate (Biotium). Cell viability was quantified using propidium iodide $(1 \mu \mathrm{g} / \mathrm{mL})$. The generated images were analysed using IncuCyte ZOOM Software Version 2016B.

\section{Western blotting}

Lysates for western blotting were prepared using standard lysis buffer (50mM Tris $\mathrm{HCl} \mathrm{pH} 7.4$, $150 \mathrm{mM} \mathrm{NaCl}, 1 \mathrm{mM}$ EDTA, $1 \%$ (v/v) Triton X-100) containing protease inhibitor (p8340, Sigma) and $0.2 \mathrm{mM}$ sodium orthovanadate. The NuPAGE SDS PAGE Gel System and NuPAGE Bis Tris Precast Gels (4-12\% and 12\%) (Life Technologies) were used to perform gel electrophoresis. Western Lightning PLUS Enhanced Chemiluminescent Substrate (PerkinElmer) was used for imaging western blots on the Vilber Lourmat Fusion chemiluminescent imaging system. Quantitative western blotting was performed using multistrip western blotting, as performed previously (Kennedy et al., 2019).

\section{NCI-H358 xenograft model}

NCI-H358 cells $\left(2 \times 10^{6}\right)$ resuspended in $100 \mu \mathrm{L}$ PBS:Matrigel were injected subcutaneously into the flanks of nude mice. Tumour growth was assessed twice weekly by calliper measurement and mice were randomized to treatment arms when tumours reached $150 \mathrm{~mm} 3$ (using the formula: width $2 \mathrm{x}$ length $\times$ 0.5). Carboplatin $(60 \mathrm{mg} / \mathrm{kg})$ was delivered by a single tail-vein injection. Dactolisib was prepared in 10\% DMSO:90\% PEG300 and administered twice-weekly at $45 \mathrm{mg} / \mathrm{kg}$ by oral gavage. All in vivo experiments, procedures and endpoints were approved by the Garvan Institute of Medical Research Animal Ethics Committee.

\section{Immunohistochemistry}

Immunohistochemistry was performed on formalin fixed paraffin embedded sections using the Leica BOND RX (Leica, Wetzlar, Germany). Slides were first dewaxed and rehydrated, followed by heat induced antigen retrieval performed with Epitope Retrieval Solution 1 BOND (Leica, Wetzlar, Germany). Primary antibodies were diluted 1:600 (P70S6K) and 1:500 (Ki67) in Leica antibody diluent and incubated for 60 min on slides. Antibody staining was completed using the Bond Polymer Refine IHC protocol and reagents (Leica, Wetzlar, Germany). Slides were counterstained on the Leica Autostainer XL (Leica, Wetzlar, Germany). Leica CV5030 Glass Coverslipper (Leica, Wetzlar, Germany) and brightfield images were taken on the Aperio CS2 Slide Scanner (Leica, Wetzlar, Germany). Quantification of Ki67 staining was performed on three fields of view for each tumour section, and quantified using the particle analysis function of Image J (v1.49). 
Targeting P70S6K overcomes platinum resistance in lung cancer - Hastings et al.

\section{FUCCI live-cell imaging}

For FUCCI live cell imaging, cells were seeded on 12 well plates and imaged using a Leica DMI6000 using a 20x NA 0.4 objective. Images were taken every $20 \mathrm{~min}$ for $72 \mathrm{~h}$. Before adding any drug (cisplatin, dactolisib or both) an image was taken in order to annotate the cell cycle phase before commencing treatment. Individual cells were tracked manually, with the colour of the nucleus annotated at each time point (Red=G1; Yellow=G1/S, Green=S/G2), the cells were also scored for nuclear envelope breakdown (NEBD) and early signs of anaphase. Mitotic length was calculated by the time period from commencement of NEBD to anaphase. Interphase length was calculated from anaphase to the next daughter cell NEBD. Only one daughter was followed and annotated. Tracking graphs were generated using Prism 7. 
Targeting P70S6K overcomes platinum resistance in lung cancer - Hastings et al.

\section{Acknowledgements}

The authors would like to acknowledge Dr Atsushi Miyawaki (Riken, Japan) for provision of the mVenus-hGeminin(1/110) and mCherry-hCdt1(30/120) constructs for FUCCI imaging. DRC was a Cancer Institute NSW Future Research Fellow (2013/FRL102).

\section{Author Contributions}

JFH conducted the experiments and wrote the paper. AGR conducted the experiments. VC, RZ and JZRH performed the animal work. YEIO and MP performed western blotting experiments. VC, $\mathrm{ADM}, \mathrm{AN}$ and DD collated the patient cohort and clinical data. AB established and supervised the live-cell imaging techniques, and edited the paper. DNW conceived the study, designed experiments, supervised AGR and edited the paper. DRC conceived the study, designed experiments, supervised JFH, JZRH, YEIO and MP, and wrote the paper.

\section{Conflict of Interests}

The authors declare no competing interests. 
Targeting P70S6K overcomes platinum resistance in lung cancer - Hastings et al.

\section{The Paper Explained}

PROBLEM: Platinum chemotherapy has been the cornerstone of treatment for lung adenocarcinoma for the last four decades, however response rates still remain below 30\%. Attempts to understand the mechanisms of innate resistance to these chemotherapy agents have been hampered by in vitro approaches that do not recapitulate in vivo pharmacokinetics. Therefore, while numerous mechanisms of resistance have been proposed, they have not translated to clinically viable options to overcome platinum resistance.

RESULTS: Using a cisplatin pulse model that closely mimics the timing and concentration of in vivo drug exposure, we firstly demonstrated that the apoptotic and signalling response induced by this pulse model was fundamentally different to that observed when cells are cultured in the continuous presence of cisplatin. Therefore, we further utilised this pulse model to profiled cisplatin-induced signalling, DNA damage and apoptotic responses across a panel of lung adenocarcinoma cell lines. Overlaying a multi-dimensional analysis of this dataset with real-time, single-cell imaging of apoptosis and cell cycle progression facilitated the identification of a P70S6K signalling axis in resistant cells, that directly opposed a late phase apoptotic response. The inhibition of P70S6K using either siRNA, or the dual PI3K/mTOR inhibitor dactolisib, sensitised resistant cells to cisplatin by preventing cell cycle arrest and promoting further DNA damage and apoptosis. Detailed mechanistic analysis demonstrated that as this cell cycle arrest was dependent upon enhanced p21 expression, this combination therapy was effective on a TP53 wildtype or TP53 null background, but not in the presence of mutant TP53.

IMPACT: The failure of many clinical trials is frequently attributed to the lack of suitable biomarkers to stratify the patient cohort. Here we demonstrate that the combination of cisplatin and dactolisib will effectively overcome platinum resistance in a strictly defined set of TP53 wildtype and TP53 null lung adenocarcinomas. This finding highlights the value of developing in vitro models that more closely match the physiological pharmacokinetics of drug exposure, and also the importance of a thorough mechanistic understanding of the signalling networks that govern drug response for the proper design and implementation of any consistently effective, patient-specific therapy. 
bioRxiv preprint doi: https://doi.org/10.1101/775924; this version posted September 20, 2019. The copyright holder for this preprint (which was not certified by peer review) is the author/funder. All rights reserved. No reuse allowed without permission.

Targeting P70S6K overcomes platinum resistance in lung cancer - Hastings et al.

\section{References}

Andersson A, Fagerberg J, Lewensohn R, Ehrsson H (1996) Pharmacokinetics of cisplatin and its monohydrated complex in humans. J Pharm Sci 85: 824-7

Bonanno L, Favaretto A, Rosell R (2014) Platinum drugs and DNA repair mechanisms in lung cancer. Anticancer Res 34: 493-501

Cerami E, Gao J, Dogrusoz U, Gross BE, Sumer SO, Aksoy BA, Jacobsen A, Byrne CJ, Heuer ML, Larsson E, Antipin Y, Reva B, Goldberg AP, Sander C, Schultz N (2012) The cBio cancer genomics portal: an open platform for exploring multidimensional cancer genomics data. Cancer Discov 2: 4014

Chen B, Yang L, Zhang R, Gan Y, Zhang W, Liu D, Chen H, Tang H (2017) Hyperphosphorylation of RPS6KB1, rather than overexpression, predicts worse prognosis in non-small cell lung cancer patients. PLoS One 12: e0182891

Chen Z, Fillmore CM, Hammerman PS, Kim CF, Wong KK (2014) Non-small-cell lung cancers: a heterogeneous set of diseases. Nat Rev Cancer 14: 535-46

Doroshow DB, Sanmamed MF, Hastings K, Politi K, Rimm DL, Chen L, Melero I, Schalper KA, Herbst RS (2019) Immunotherapy in Non-Small Cell Lung Cancer: Facts and Hopes. Clin Cancer Res 25: 4592-4602

Engeland K (2018) Cell cycle arrest through indirect transcriptional repression by p53: I have a DREAM. Cell Death Differ 25: 114-132

Fey D, Halasz M, Dreidax D, Kennedy SP, Hastings JF, Rauch N, Munoz AG, Pilkington R, Fischer M, Westermann F, Kolch W, Kholodenko BN, Croucher DR (2015) Signaling pathway models as biomarkers: Patient-specific simulations of JNK activity predict the survival of neuroblastoma patients. Sci Signal 8: ra130

Galan-Moya EM, de la Cruz-Morcillo MA, Llanos Valero M, Callejas-Valera JL, Melgar-Rojas P, Hernadez Losa J, Salcedo M, Fernandez-Aramburo A, Ramon y Cajal S, Sanchez-Prieto R (2011) Balance between MKK6 and MKK3 mediates p38 MAPK associated resistance to cisplatin in NSCLC. PLoS One 6: e28406

Gao J, Aksoy BA, Dogrusoz U, Dresdner G, Gross B, Sumer SO, Sun Y, Jacobsen A, Sinha R, Larsson E, Cerami E, Sander C, Schultz N (2013) Integrative analysis of complex cancer genomics and clinical profiles using the cBioPortal. Sci Signal 6: pl1

Gire V, Dulic V (2015) Senescence from G2 arrest, revisited. Cell Cycle 14: 297-304

Guegan JP, Ezan F, Gailhouste L, Langouet S, Baffet G (2014) MEK1/2 overactivation can promote growth arrest by mediating ERK1/2-dependent phosphorylation of p70S6K. J Cell Physiol 229: 90315

Gyorffy B, Surowiak P, Budczies J, Lanczky A (2013) Online survival analysis software to assess the prognostic value of biomarkers using transcriptomic data in non-small-cell lung cancer. PLoS One 8: e82241

Hay M, Thomas DW, Craighead JL, Economides C, Rosenthal J (2014) Clinical development success rates for investigational drugs. Nat Biotechnol 32: 40-51

Hernandez Losa J, Parada Cobo C, Guinea Viniegra J, Sanchez-Arevalo Lobo VJ, Ramon y Cajal S, Sanchez-Prieto R (2003) Role of the p38 MAPK pathway in cisplatin-based therapy. Oncogene 22: 3998-4006

Hoffmann EK, Lambert IH (2014) Ion channels and transporters in the development of drug resistance in cancer cells. Philos Trans R Soc Lond B Biol Sci 369: 20130109

Holz MK (2012) The role of S6K1 in ER-positive breast cancer. Cell Cycle 11: 3159-65

Hsu CM, Lin PM, Tsai YT, Tsai MS, Tseng CH, Lin SF, Yang MY (2018) NVP-BEZ235, a dual PI3K-mTOR inhibitor, suppresses the growth of FaDu hypopharyngeal squamous cell carcinoma and has a synergistic effect with Cisplatin. Cell Death Discov 4: 57

Huang JC, Cui ZF, Chen SM, Yang LJ, Lian HK, Liu B, Su ZH, Liu JS, Wang M, Hu ZB, Ouyang JY, Li QC, Lu H (2018) NVP-BEZ235 synergizes cisplatin sensitivity in osteosarcoma. Oncotarget 9: 10483-10496

Ip CK, Wong AS (2012) Exploiting p70 S6 kinase as a target for ovarian cancer. Expert Opin Ther Targets 16: 619-30 
bioRxiv preprint doi: https://doi.org/10.1101/775924; this version posted September 20, 2019. The copyright holder for this preprint (which was not certified by peer review) is the author/funder. All rights reserved. No reuse allowed without permission.

Targeting P70S6K overcomes platinum resistance in lung cancer - Hastings et al.

Jamieson ER, Lippard SJ (1999) Structure, Recognition, and Processing of Cisplatin-DNA Adducts. Chem Rev 99: 2467-98

Johansen MJ, Thapar N, Newman RA, Madden T (2002) Use of microdialysis to study platinum anticancer agent pharmacokinetics in preclinical models. J Exp Ther Oncol 2: 163-73

Kennedy SP, Han JZR, Portman N, Nobis M, Hastings JF, Murphy KJ, Latham SL, Cadell AL, Miladinovic D, Marriott GR, O'Donnell YEI, Shearer RF, Williams JT, Munoz AG, Cox TR, Watkins DN, Saunders DN, Timpson P, Lim E, Kolch W et al. (2019) Targeting promiscuous heterodimerization overcomes innate resistance to ERBB2 dimerization inhibitors in breast cancer. Breast Cancer Res 21: 43

Kim R, Keam B, Hahn S, Ock CY, Kim M, Kim TM, Kim DW, Heo DS (2019) First-line Pembrolizumab Versus Pembrolizumab Plus Chemotherapy Versus Chemotherapy Alone in Nonsmall-cell Lung Cancer: A Systematic Review and Network Meta-analysis. Clin Lung Cancer

Lane HA, Fernandez A, Lamb NJ, Thomas G (1993) p70s6k function is essential for G1 progression. Nature 363: 170-2

Lindeman NI, Cagle PT, Aisner DL, Arcila ME, Beasley MB, Bernicker EH, Colasacco C, Dacic S, Hirsch FR, Kerr K, Kwiatkowski DJ, Ladanyi M, Nowak JA, Sholl L, Temple-Smolkin R, Solomon B, Souter LH, Thunnissen E, Tsao MS, Ventura CB et al. (2018) Updated Molecular Testing Guideline for the Selection of Lung Cancer Patients for Treatment With Targeted Tyrosine Kinase Inhibitors: Guideline From the College of American Pathologists, the International Association for the Study of Lung Cancer, and the Association for Molecular Pathology. J Thorac Oncol 13: 323-358

Marini KD, Croucher DR, McCloy RA, Vaghjiani V, Gonzalez-Rajal A, Hastings JF, Chin V, Szczepny A, Kostyrko K, Marquez C, Jayasekara WSN, Alamgeer M, Boolell V, Han JZR, Waugh T, Lee HC, Oakes SR, Kumar B, Harrison CA, Hedger MP et al. (2018) Inhibition of activin signaling in lung adenocarcinoma increases the therapeutic index of platinum chemotherapy. Science translational medicine 10

Moon du G, Lee SE, Oh MM, Lee SC, Jeong SJ, Hong SK, Yoon CY, Byun SS, Park HS, Cheon J (2014) NVP-BEZ235, a dual PI3K/mTOR inhibitor synergistically potentiates the antitumor effects of cisplatin in bladder cancer cells. Int J Oncol 45: 1027-35

Moser BA, Dennis PB, Pullen N, Pearson RB, Williamson NA, Wettenhall RE, Kozma SC, Thomas G (1997) Dual requirement for a newly identified phosphorylation site in p70s6k. Mol Cell Biol 17: 5648-55

Nozawa H, Watanabe T, Nagawa H (2007) Phosphorylation of ribosomal p70 S6 kinase and rapamycin sensitivity in human colorectal cancer. Cancer Lett 251: 105-13

Pabla N, Dong Z (2008) Cisplatin nephrotoxicity: mechanisms and renoprotective strategies. Kidney Int 73: 994-1007

Pereira L, Igea A, Canovas B, Dolado I, Nebreda AR (2013) Inhibition of p38 MAPK sensitizes tumour cells to cisplatin-induced apoptosis mediated by reactive oxygen species and JNK. EMBO Mol Med 5: 1759-74

Pilkington G, Boland A, Brown T, Oyee J, Bagust A, Dickson R (2015) A systematic review of the clinical effectiveness of first-line chemotherapy for adult patients with locally advanced or metastatic non-small cell lung cancer. Thorax 70: 359-67

Sahin F, Kannangai R, Adegbola O, Wang J, Su G, Torbenson M (2004) mTOR and P70 S6 kinase expression in primary liver neoplasms. Clin Cancer Res 10: 8421-5

Sakaue-Sawano A, Kurokawa H, Morimura T, Hanyu A, Hama H, Osawa H, Kashiwagi S, Fukami K, Miyata T, Miyoshi H, Imamura T, Ogawa M, Masai H, Miyawaki A (2008) Visualizing spatiotemporal dynamics of multicellular cell-cycle progression. Cell 132: 487-98

Sarin N, Engel F, Rothweiler F, Cinatl J, Michaelis M, Frotschl R, Frohlich H, Kalayda GV (2018) Key Players of Cisplatin Resistance: Towards a Systems Pharmacology Approach. Int J Mol Sci 19

Shen DW, Pouliot LM, Hall MD, Gottesman MM (2012) Cisplatin resistance: a cellular self-defense mechanism resulting from multiple epigenetic and genetic changes. Pharmacol Rev 64: 706-21

Stewart DJ (2007) Mechanisms of resistance to cisplatin and carboplatin. Crit Rev Oncol Hematol 63: 12-31

Sunami T, Byrne N, Diehl RE, Funabashi K, Hall DL, Ikuta M, Patel SB, Shipman JM, Smith RF, Takahashi I, Zugay-Murphy J, Iwasawa Y, Lumb KJ, Munshi SK, Sharma S (2010) Structural basis 
bioRxiv preprint doi: https://doi.org/10.1101/775924; this version posted September 20, 2019. The copyright holder for this preprint (which was not certified by peer review) is the author/funder. All rights reserved. No reuse allowed without permission.

Targeting P70S6K overcomes platinum resistance in lung cancer - Hastings et al.

of human p70 ribosomal S6 kinase-1 regulation by activation loop phosphorylation. J Biol Chem 285: 4587-94 
Targeting P70S6K overcomes platinum resistance in lung cancer - Hastings et al.

\section{Figure Legends:}

Figure 1: Multiplexed analysis of cisplatin-induced signalling. (A) Schematic of the cisplatin pulse model $(5 \mu \mathrm{g} / \mathrm{mL}, 2 \mathrm{~h})$ and continuous pulse model $(5 \mu \mathrm{g} / \mathrm{mL}, 72 \mathrm{~h})$. (B) Live-cell imaging of A549 cells treated with either continuously, or with a cisplatin pulse. Apoptotic cells were identified by uptake of propidium iodide (mean $\pm \mathrm{SD}$ ). (C) Multiplexed analysis of key DNA damage, apoptosis and signalling proteins in A549 cells treated either continuously, or with a cisplatin pulse $(\mathrm{n}=3$, mean). (D) Apoptosis measured by propidium iodide staining for the sub-G1 population, performed $72 \mathrm{~h}$ following a cisplatin pulse across a panel of lung adenocarcinoma cell lines, as indicated $(\mathrm{n}=3$, mean $\pm \mathrm{SD}, * * * \mathrm{p}<0.001, * * \mathrm{p}<0.01, * \mathrm{p}<0.05$ ). (E) Representative images of anti-cisplatin antibody staining in A549 cells following a cisplatin pulse, and quantification of nuclear cisplatin-DNA adducts across the cell line panel $(\mathrm{n} \geq 100$, mean $\pm \mathrm{SD}$. $* * * \mathrm{p}<0.001$, ** $\mathrm{p}<0.01)$. All treatment conditions (red) are significantly different from control (blue), $\mathrm{p}<0.001$. (F) Multiplexed analysis of DNA damage, apoptosis and signalling pathways following a cisplatin pulse across a panel of lung adenocarcinoma cell lines, as indicated $(\mathrm{n}=3$, mean).

Figure 2: Principal component analysis. (A) Visualisation of component 1 against component 2 for the cisplatin induced signalling analysis across the cell line panel. (B) Distribution of the analytes according to their weighting within component 1 and 2. (C) Western blotting for selected analytes across the cell panel prior to, and $48 \mathrm{~h}$ post a cisplatin pulse. (D) Visualisation of component 3 against component 3 for the cisplatin induced signalling analysis across the cell line panel. (E) Distribution of the analytes according to their weighting within component 1 and 2.

Figure 3: Visualising and targeting mechanisms of cisplatin resistance. (A) An overlay of live-cell imaging of apoptosis following a cisplatin pulse on top of the PCA plot of component 3 against component 4. (B) Schematic of the cisplatin pulse model, with the addition of small molecule inhibitors, and outline of sample collection for apoptosis assays and western blotting. (C,D) Apoptosis measured by propidium iodide staining for the sub-G1 population in A549 and NCI-H358 cells, performed $72 \mathrm{~h}$ following a cisplatin pulse with the addition of small molecule inhibitors $(1 \mu \mathrm{M})$ as indicated ( $\mathrm{n}=3$, mean $\pm \mathrm{SD}$ ). (E) Western blotting on lysates from NCI-H358 and NCI-H1299 cells following a cisplatin pulse, with the addition of dactolisib $(1 \mu \mathrm{M})$, as indicated. (F) Schematic of the cisplatin pulse model, with the addition of siRNA pre-treatment, and outline of sample collection for apoptosis assays and western blotting. (G) Western blotting on lysates from NCI-H358 cells, treated with P70S6K or control siRNA, as indicated, prior to and following a cisplatin pulse $(n=3$, mean \pm $\mathrm{SD})$. (H) Apoptosis measured by propidium iodide staining for the sub-G1 population in NCI-H358 cells, treated with P70S6K, control siRNA or dactolisib, as indicated, performed $72 \mathrm{~h}$ following a cisplatin pulse ( $\mathrm{n}=3$, mean $\pm \mathrm{SD}$ ). (I) Tumour growth in nude mice bearing NCI-H358 xenografts with continuous treatment of vehicle control or dactolisib (45 mg/kg) prior to, and following a single dose 
Targeting P70S6K overcomes platinum resistance in lung cancer - Hastings et al.

of carboplatin $(60 \mathrm{mg} / \mathrm{kg})(\mathrm{n} \geq 4$, mean \pm SEM). (J) Quantification of necrosis in NCI-H358 xenografts following the treatment described in (I) ( $\mathrm{n} \geq 4$, mean $\pm \mathrm{SD}$ ). For all experiments, $* * * \mathrm{p}<0.001$, ** $\mathrm{p}<0.01, * \mathrm{p}<0.05$.

Figure 4: P70S6K in lung adenocarcinoma. (A) The frequency of somatic mutations and mRNA over-expression for the RPS6KB1, RPS6KB2 and TP53 genes in a publically available cohort of lung adenocarcinoma patients (cBioPortal). (B) The association between RPS6KB1 and RPS6KB2 mRNA expression and overall patient survival in a publically available patient cohort (KM Plotter). (C) Representative images of P70S6K immuno-histochemistry staining from a cohort of 52 lung adenocarcinoma patients (Scale bar $=100 \mu \mathrm{M}$ ). (D) ) Survival analysis based upon P70S6K staining in this cohort. (E) The association between tumour P70S6K staining intensity (H-Score) and patients that underwent a partial response (PR), or presented with stable disease (SD) or progressive disease (PD). (F) The association between tumour P70S6K staining intensity and tumour stage. (G) P70S6K staining in 8 matched patient samples from diagnosis and relapse $(n=8, * p<0.05)$.

Figure 5: FUCCI analysis of cell cycle progression. (A) Live-cell imaging of the FUCCI biosensor proteins mVenus-hGeminin(1/110) and mCherry-hCdt1(30/120), stably expressed by the A549, NCIH1573 and NCI-H358 cell lines. Images were taken every $20 \mathrm{~min}$ for $72 \mathrm{~h}$ under control conditions, or following a cisplatin pulse $(5 \mu \mathrm{g} / \mathrm{mL}, 2 \mathrm{~h})$ in the presence or absence of dactolisib $(1 \mu \mathrm{M})$. (B) Quantification of the length of each cell cycle phase under each treatment condition ( $n=17-175$, mean $\pm \mathrm{SD}), * * * * \mathrm{p}<0.0001, * * * \mathrm{p}<0.001, * * \mathrm{p}<0.01, * \mathrm{p}<0.05$. (C) Quantification of fate of each cell; including G1 arrest before mitosis (G1 ABM), G1 arrest after mitosis (G1 AAM), death before mitosis (DBM) and death after mitosis (DAM). (D) Survival curves indicating the proportion of viable cells over time under each treatment condition.

Figure 6: Response to dactolisib is dependent upon TP53 mutation status. (A) Western blotting on lysates from NCI-H358 and NCI-H1299 cells following a cisplatin pulse, with the addition of dactolisib $(1 \mu \mathrm{M})$, as indicated. (B) Quantification of effects of dactolisib upon cisplatin induced p63 and $\mathrm{p} 21$ expression $(\mathrm{n}=3$, mean $\pm \mathrm{SD})$. (C) Western blotting on lysates from NCI-H358 cells, treated with P70S6K or control siRNA, as indicated, prior to and following a cisplatin pulse $(n=3$, mean \pm $\mathrm{SD})$. (D) Apoptosis measured by propidium iodide staining for the sub-G1 population performed $72 \mathrm{~h}$ following a cisplatin pulse with the addition of dactolisib $(1 \mu \mathrm{M})$ as indicated $(\mathrm{n}=3$, mean $\pm \mathrm{SD})$. (E) Western blotting on lysates from A549 and NCI-H1573 cells, $48 \mathrm{~h}$ following a cisplatin pulse, with the addition of dactolisib $(1 \mu \mathrm{M})$, as indicated $(\mathrm{n}=3$, mean \pm SD). (F) Western blotting across a second panel of lung adenocarcinoma cell lines. (G) Correlation between P70S6K phosphorylation and apoptosis measured by propidium iodide staining for the sub-G1 population, performed $72 \mathrm{~h}$ following a cisplatin pulse $(n=3$, mean $\pm S D)$. 
Targeting P70S6K overcomes platinum resistance in lung cancer - Hastings et al.

Figure 7: Schematic outlining the effect of P70S6K on cisplatin induced cell cycle arrest on TP53 mutation specific backgrounds. 


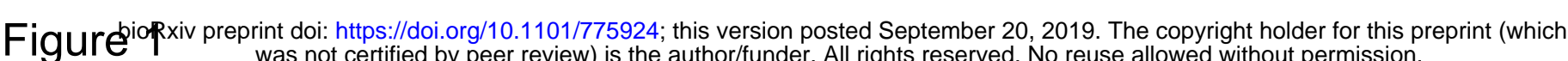

A
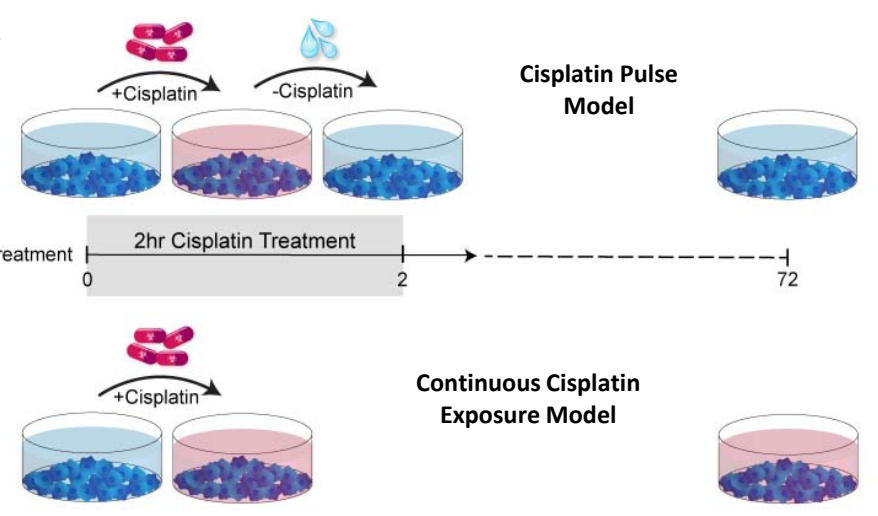

Treatment $72 \mathrm{hr}$ Cisplatin Treatment

D

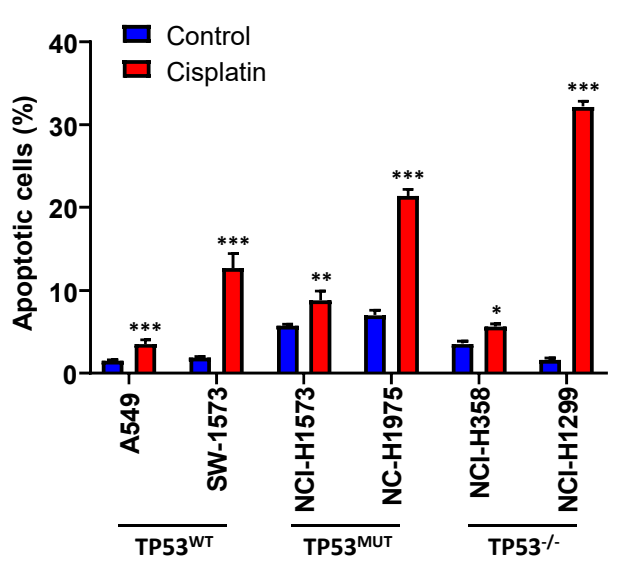

E
B
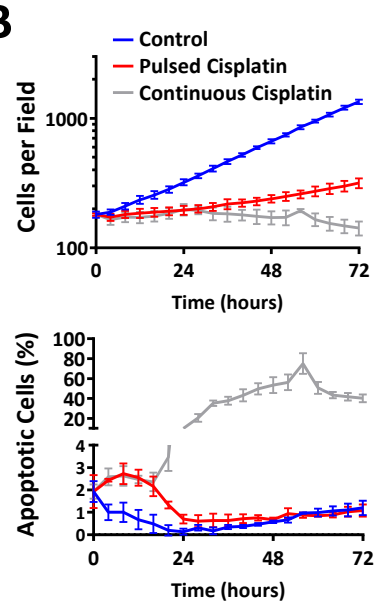

C

Pulsed Continuous Cisplatin Cisplatin
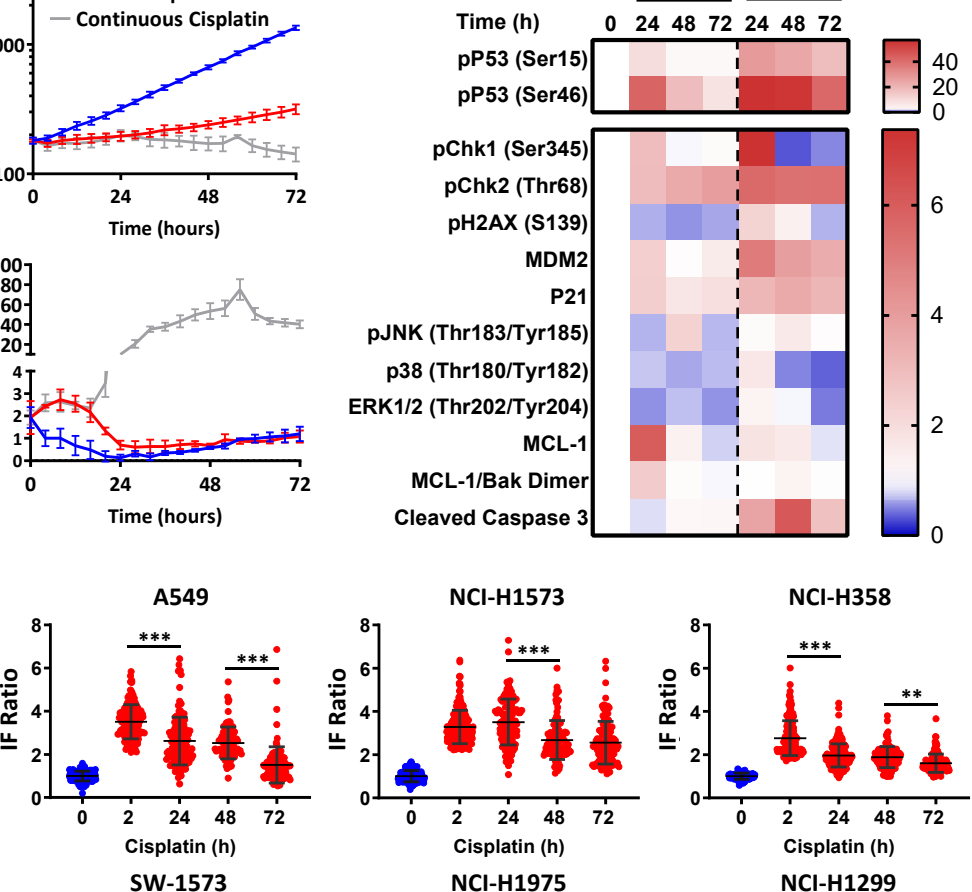

Cisplatin Pulse (2h)
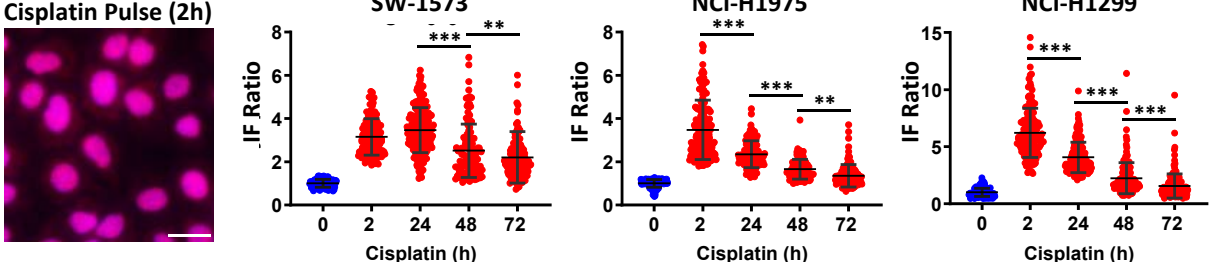

$\mathbf{F}$ A549 (TP53 ${ }^{\text {WT }}$ ) SW-1573 (TP53 ${ }^{\mathrm{WT}}$ )

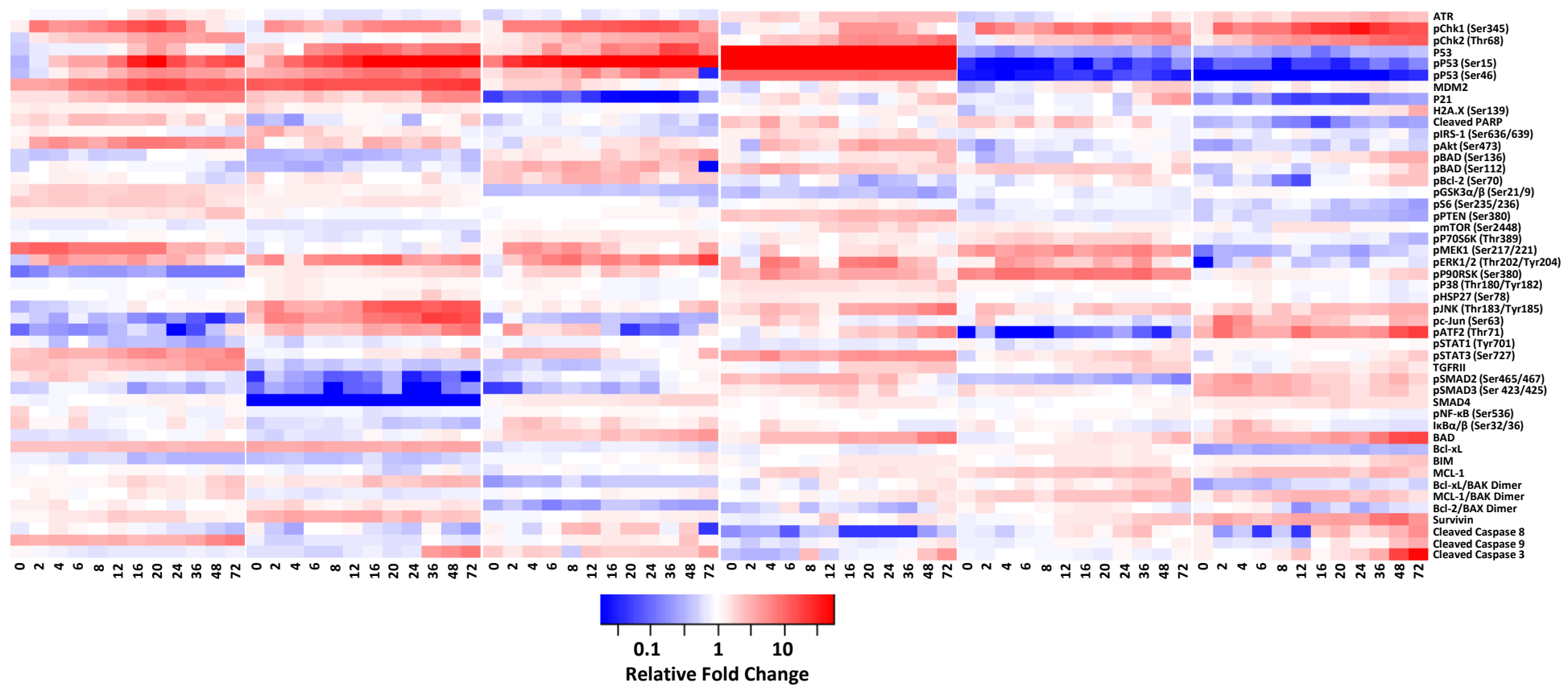


Figure pioRxiv preprint doi: https://doi.org/10.1101/775924; this version posted September 20, 2019. The copyright holder for this preprint (which
was not certified by peer review) is the author/funder. All rights reserved. No reuse allowed without permission.
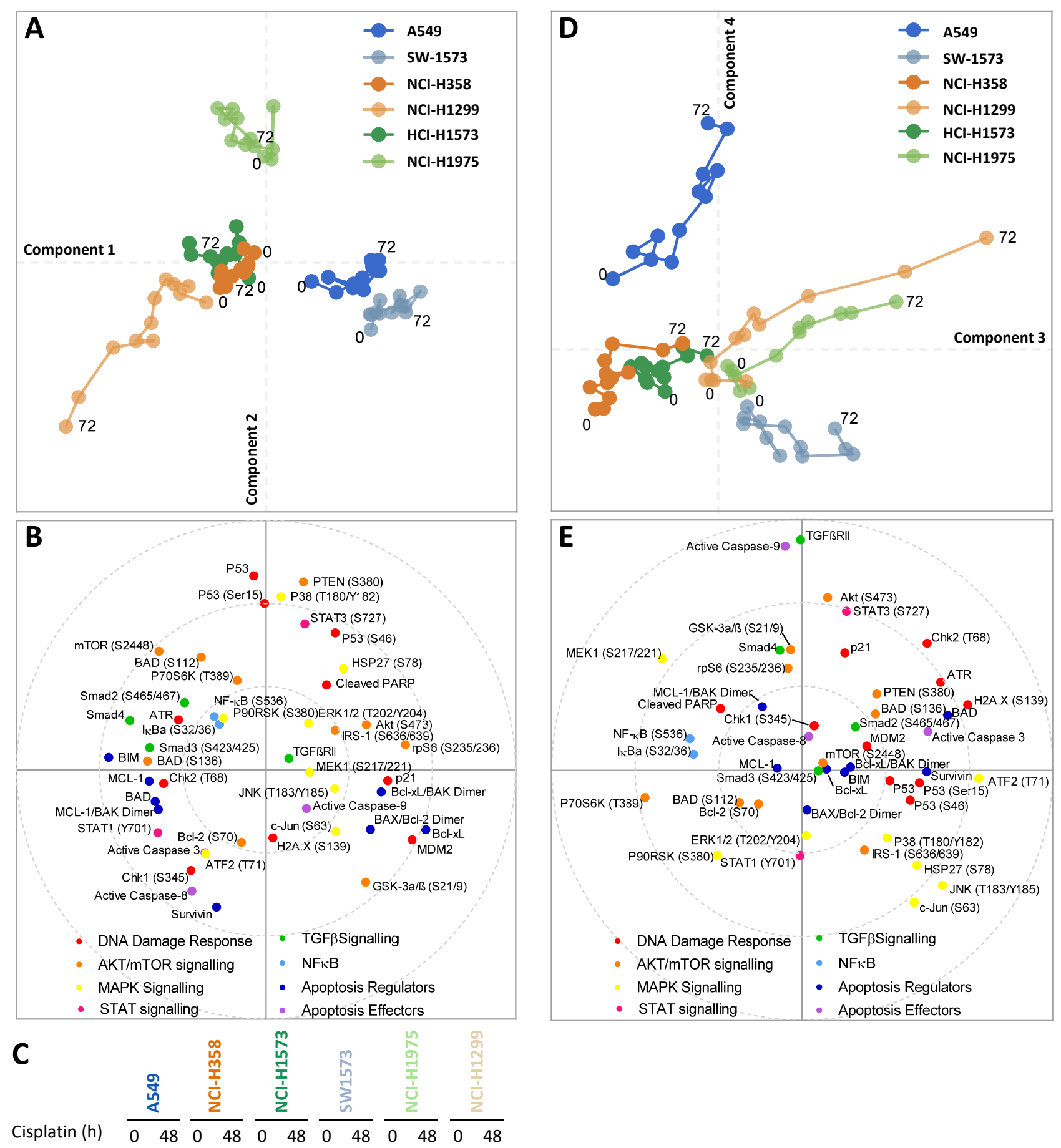

P53

p21

pSTAT3 ${ }^{5727}$

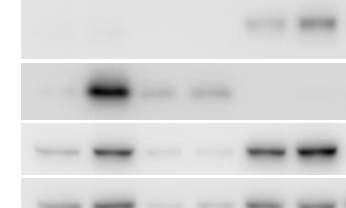

pAkt $^{\text {S473 }}$

pNF-kB ${ }^{\mathrm{S536}}$

pMEK $^{\mathrm{S217} / \mathrm{S} 221}$

pP70S6K $\mathrm{K}^{\text {T389 }}$

P70S6K

$\mathrm{pS6}^{\mathrm{S235/236}}$

S6

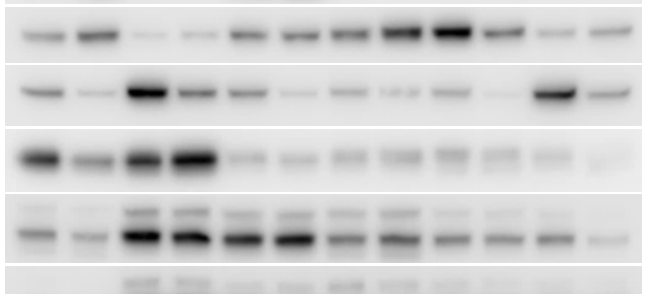

pATF2 ${ }^{\mathrm{T} 71}$

$\mathrm{pJNK}^{\mathrm{T} 183 / \mathrm{Y} 185}$

Actin 


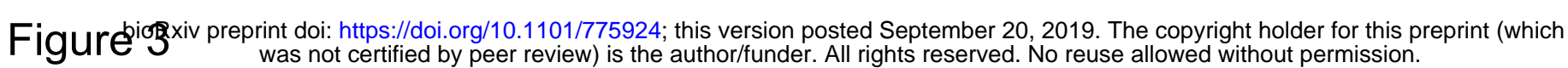

A

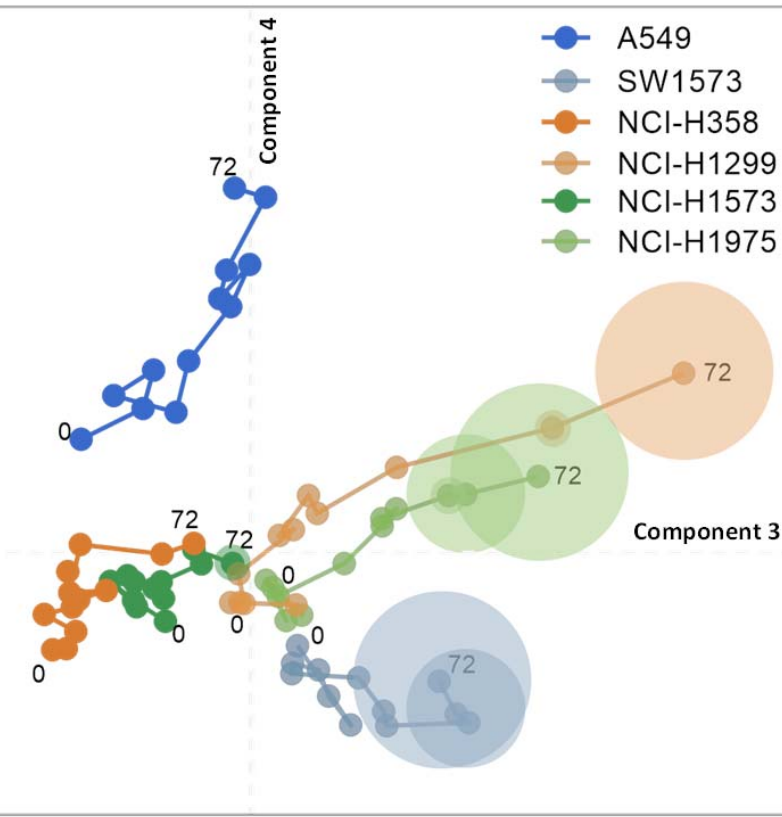

B

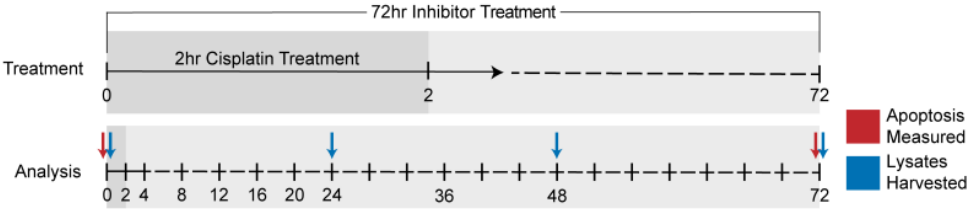

C

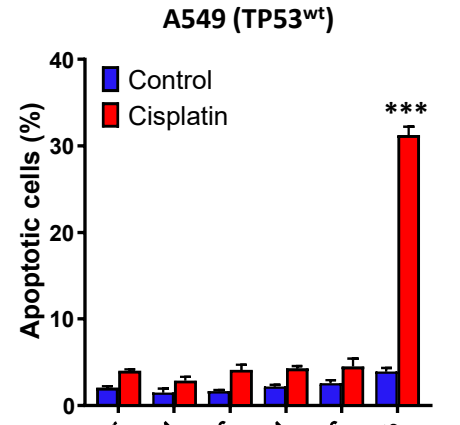

D

NCl-H358 (TP53-/-)

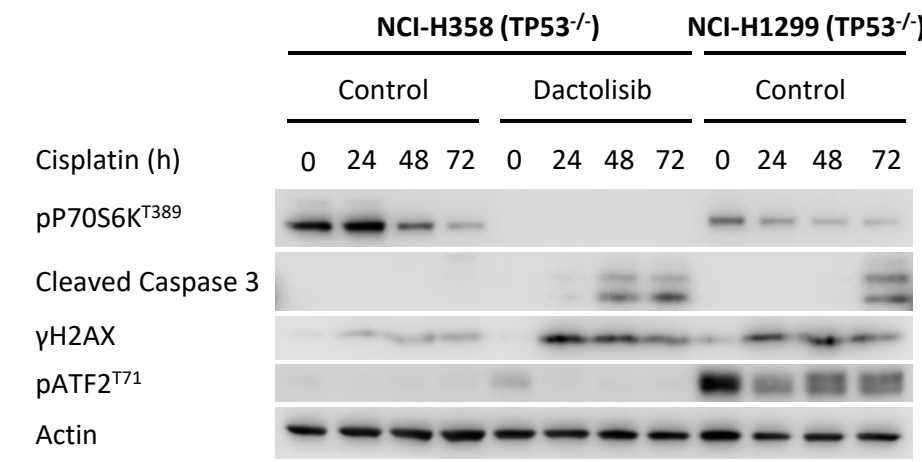

$\mathbf{F}$

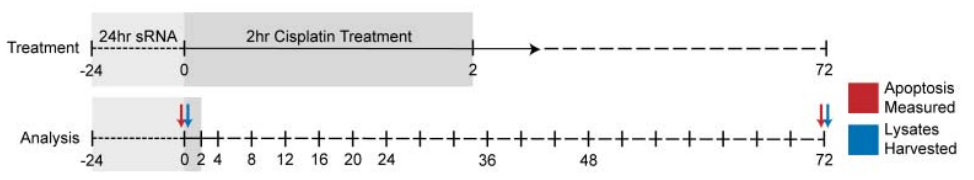

G

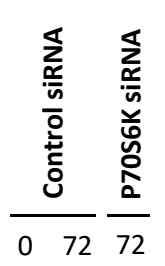

P70S6K

YH2A.X

Cleaved

Caspase 3

Actin
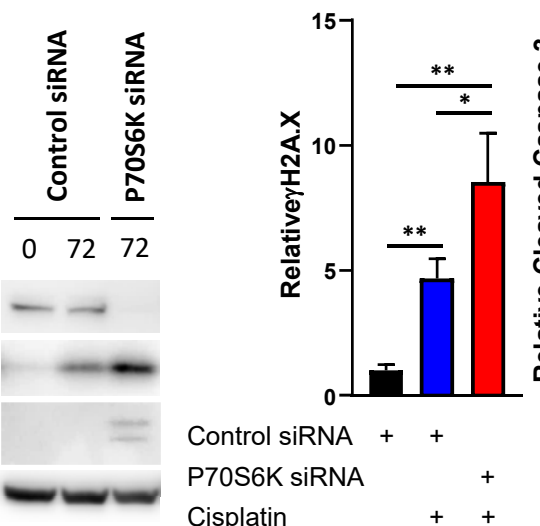

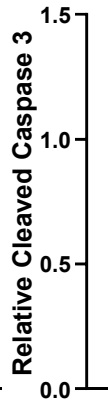

Control siRNA + P70S6K siRNA Cisplatin
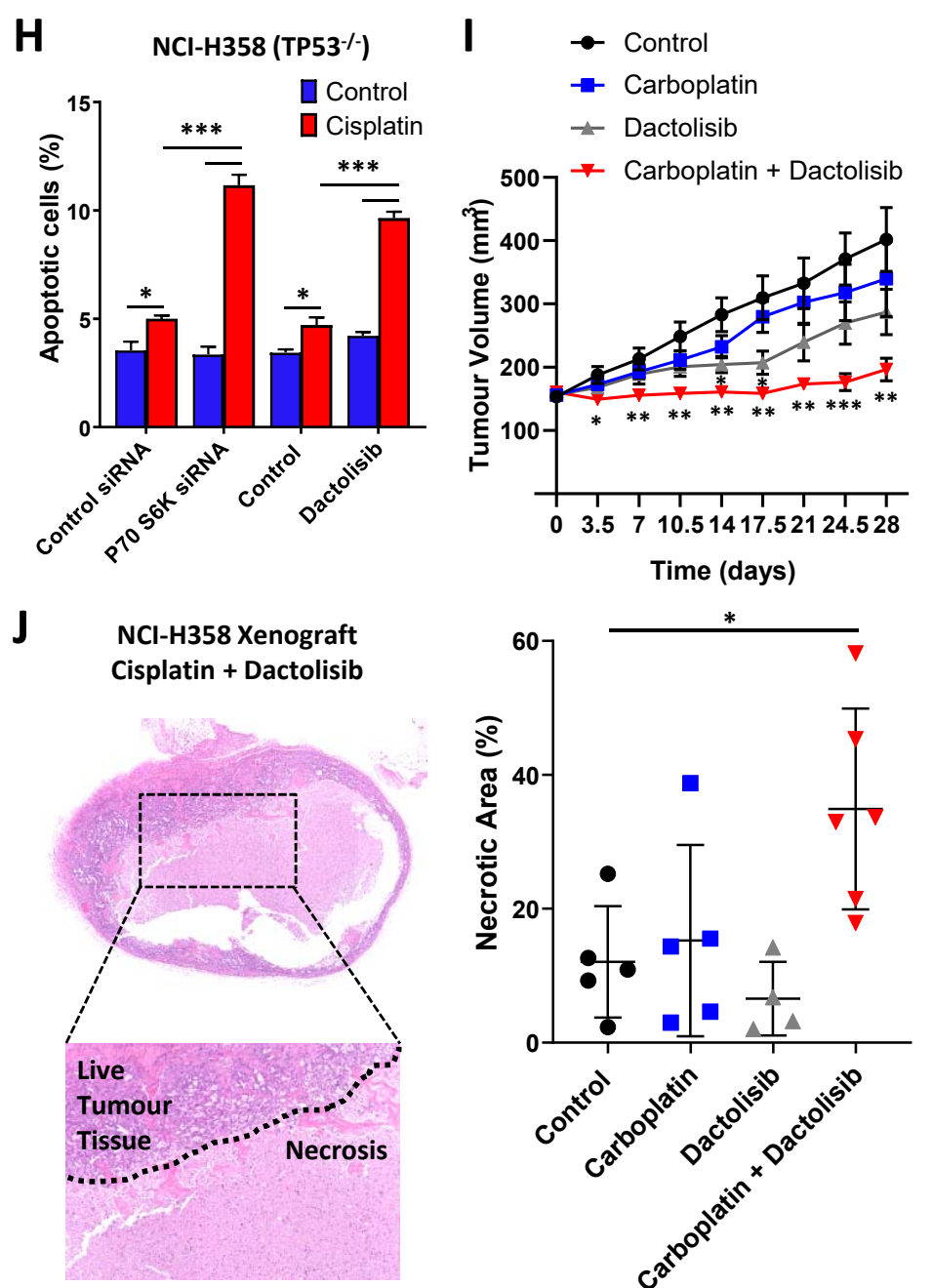


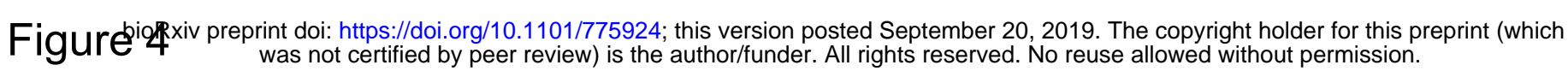

A

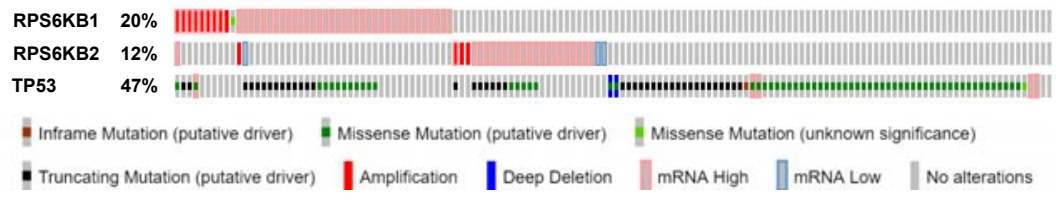

B

RPS6KB1 (P70S6Ka)

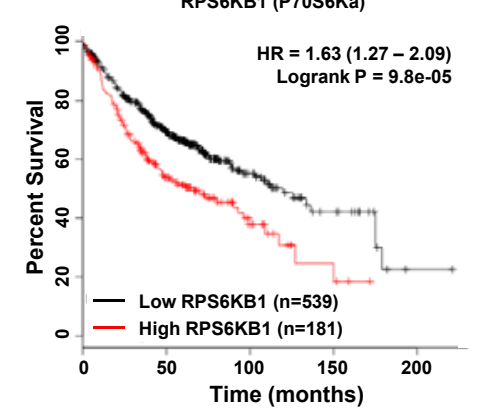

C

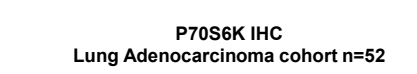

D
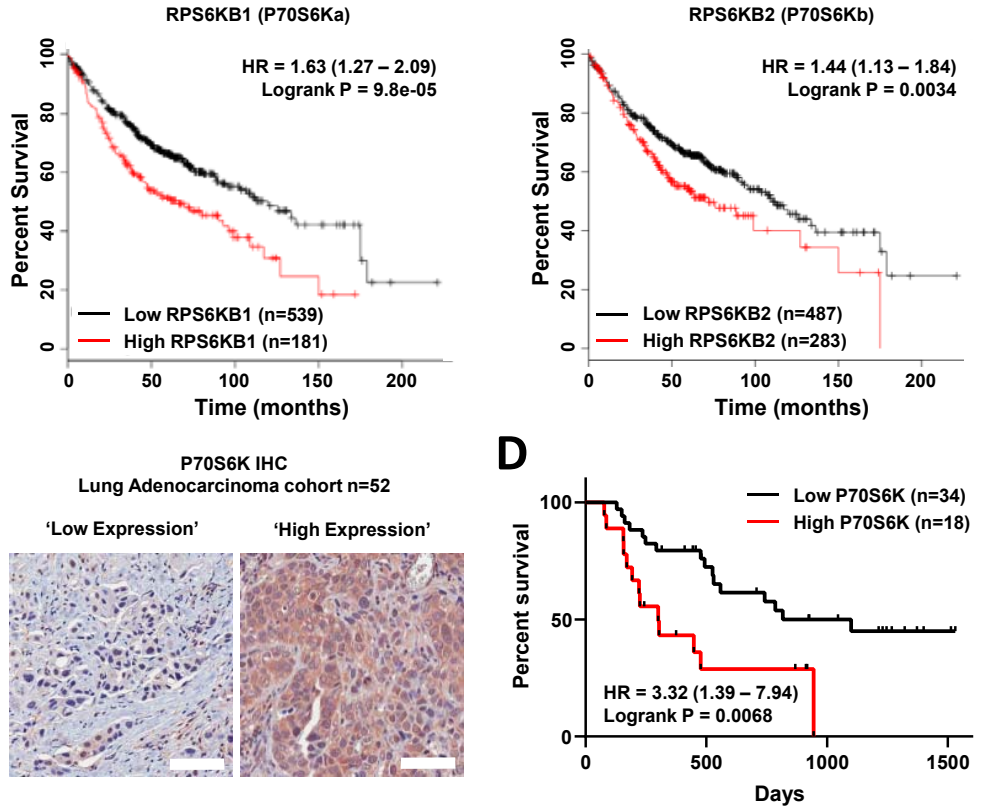

E

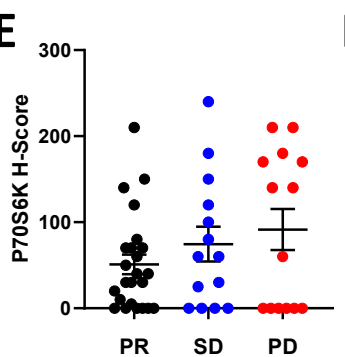

F

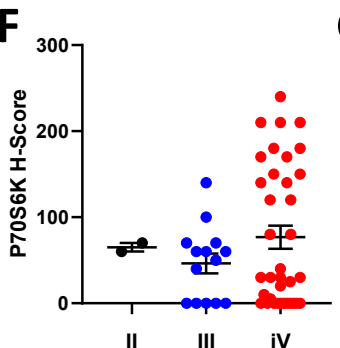

G

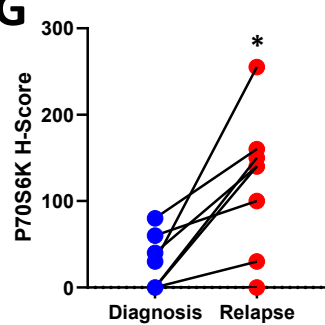


A
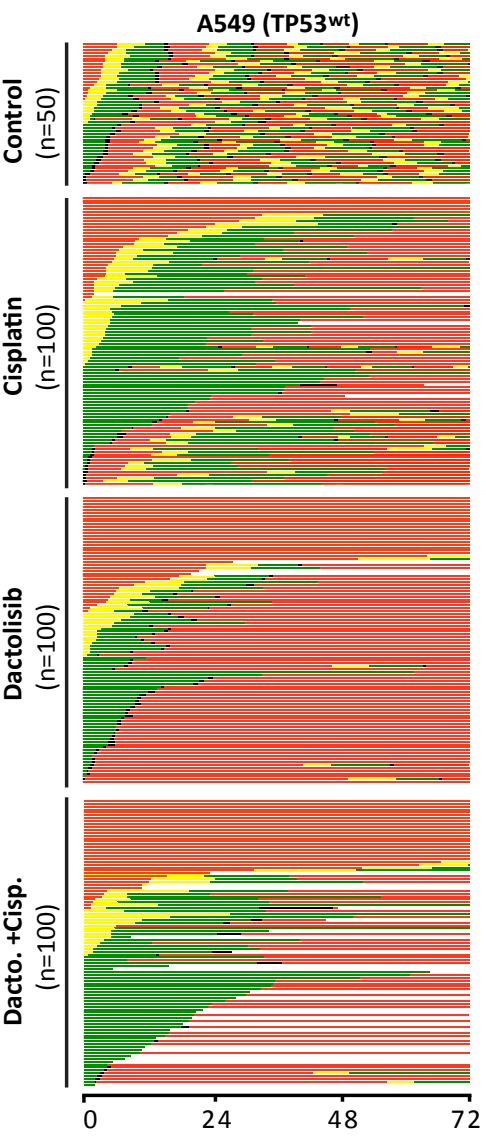

B
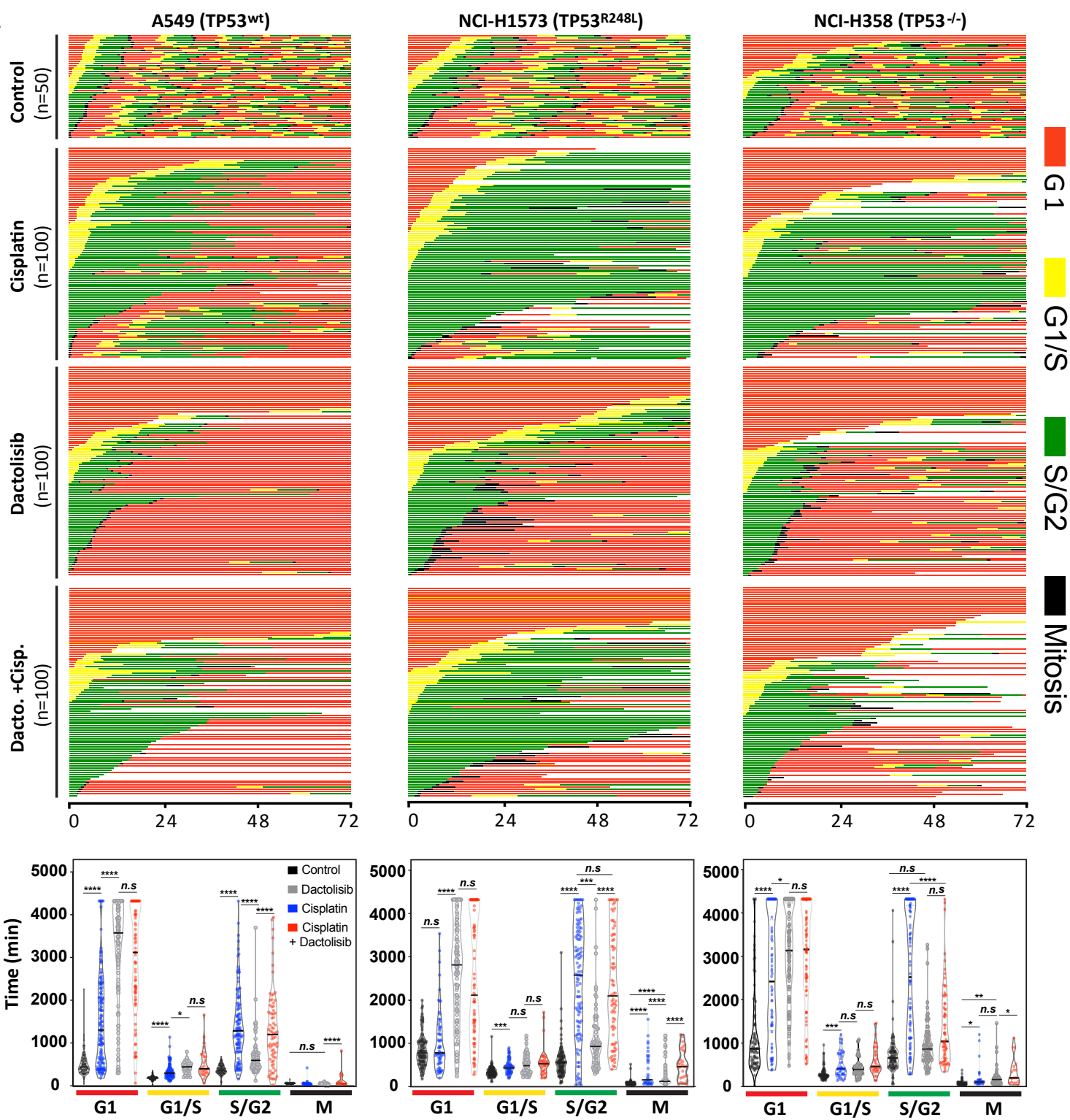

C
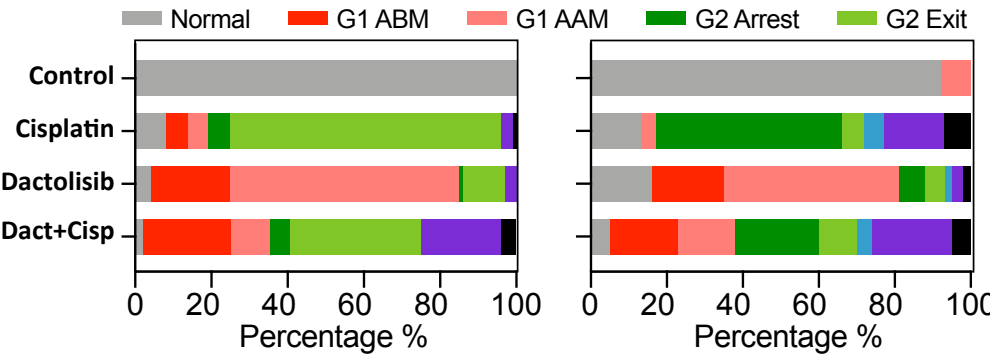

D
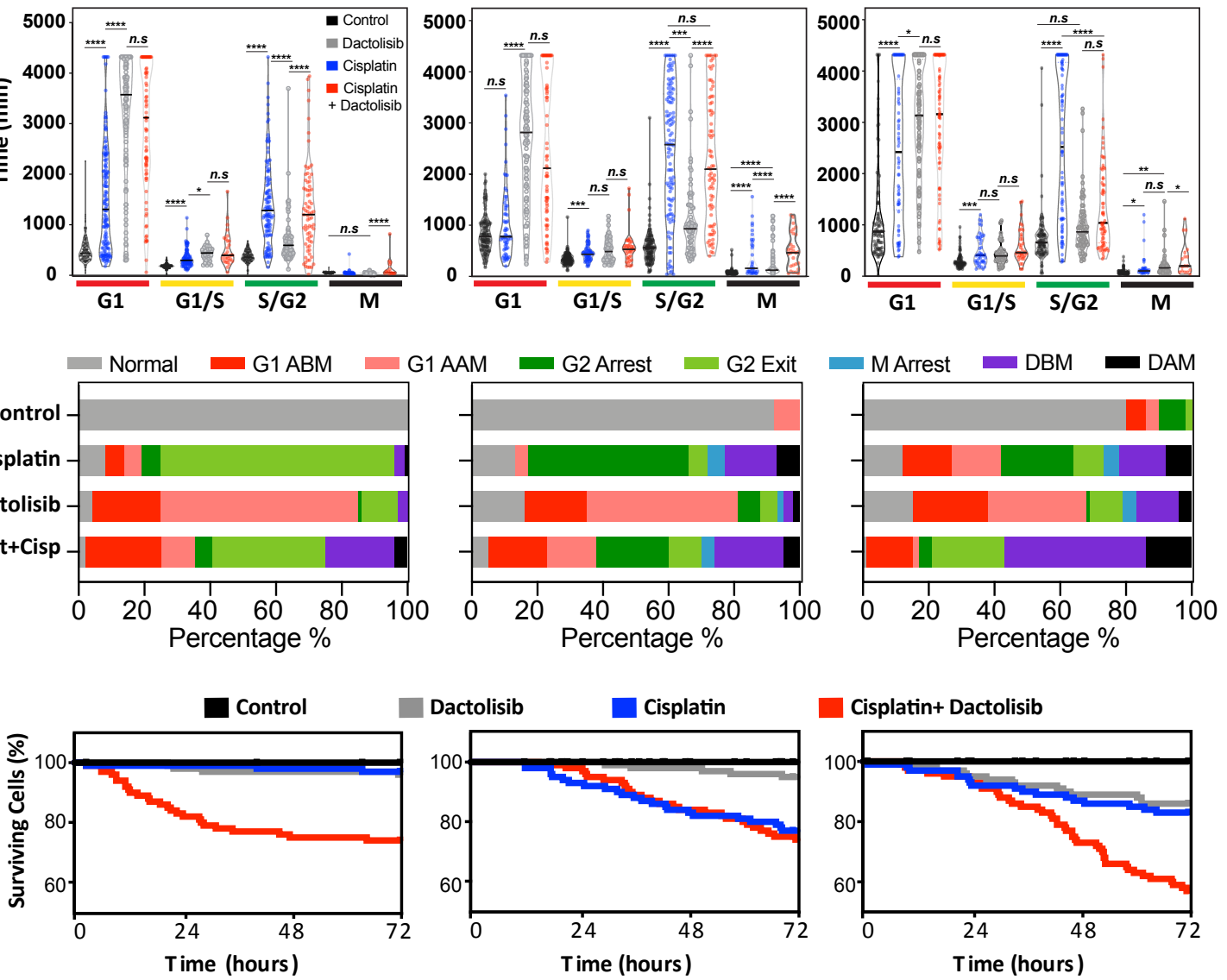

Cisplatin+ Dactolisib

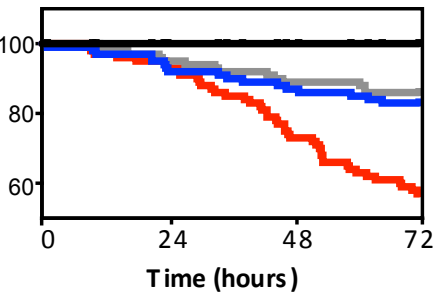


Figure
biginiv preprint doi: https://doi.org/10.1101/775924; this version posted September 20, 2019. The copyright holder for this preprint (which
was not certified by peer review) is the author/funder. All rights reserved. No reuse allowed without permission.

A

$\frac{\left.\text { NCI-H358 (TP53 }{ }^{-/}\right)}{\text {Control }} \frac{\text { Dactolisib }}{0244872} \frac{\text { Control }}{0244872} \frac{\text { Cl-H1299 (TP53-/) }}{0.2448 \quad 72}$

Cisplatin (h) $0 \begin{array}{llllllllllll}0 & 24 & 48 & 72 & 0 & 24 & 48 & 72 & 0 & 24 & 48 & 72\end{array}$

p21

p63

$---$

Actin
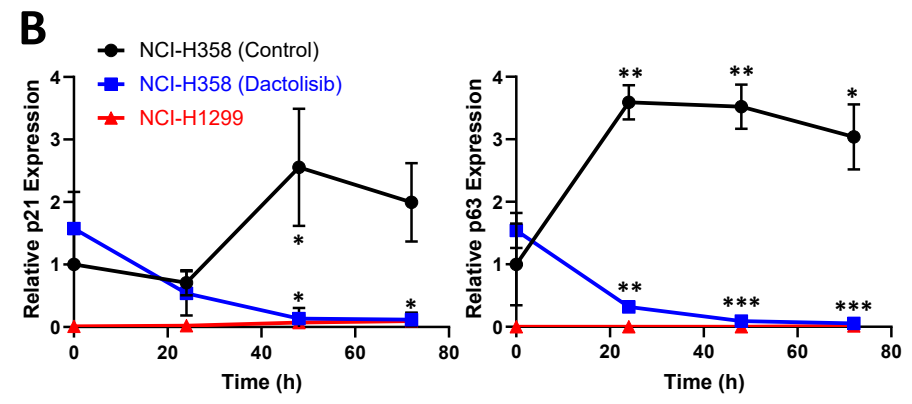

C NCl-H358 (TP53-- - )

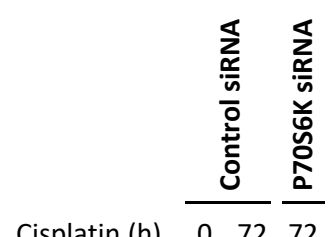

Cisplatin (h) $0 \quad 72 \quad 72$

P70S6K

p63

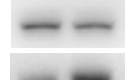

p21
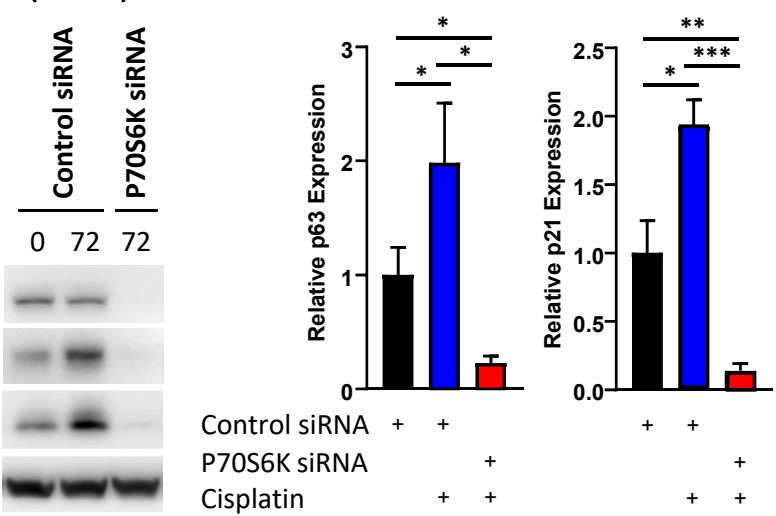

D

- Control

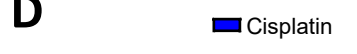

P70s6K SiRNA
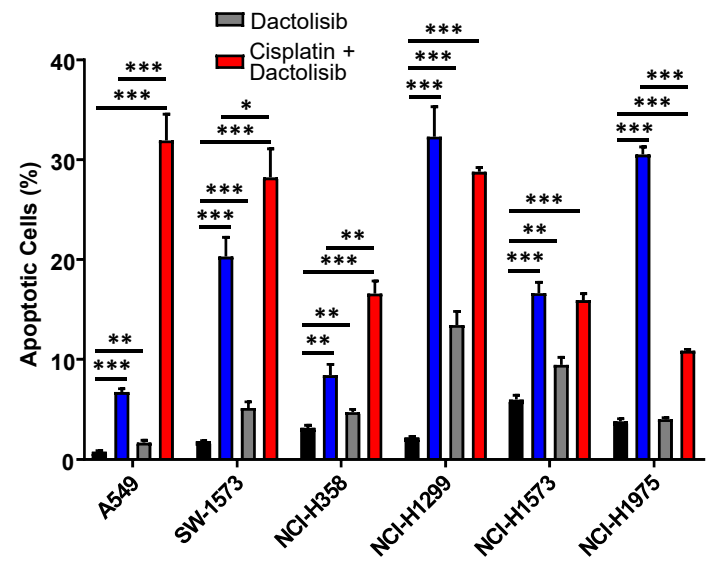

E

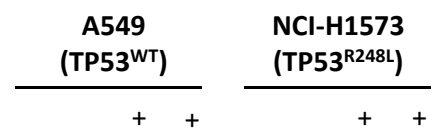

Dactolisib

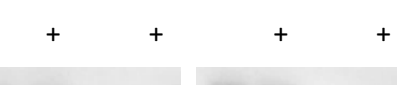

pP70S6K

P70S6K

p53

p21

YH2A.X

Cleaved

Caspase 3

Cleaved

Caspase 7

Actin

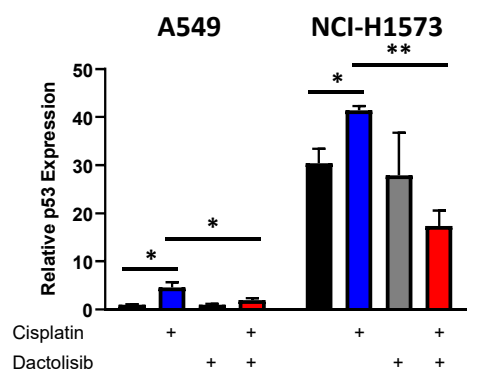

A549

NCI-H1573
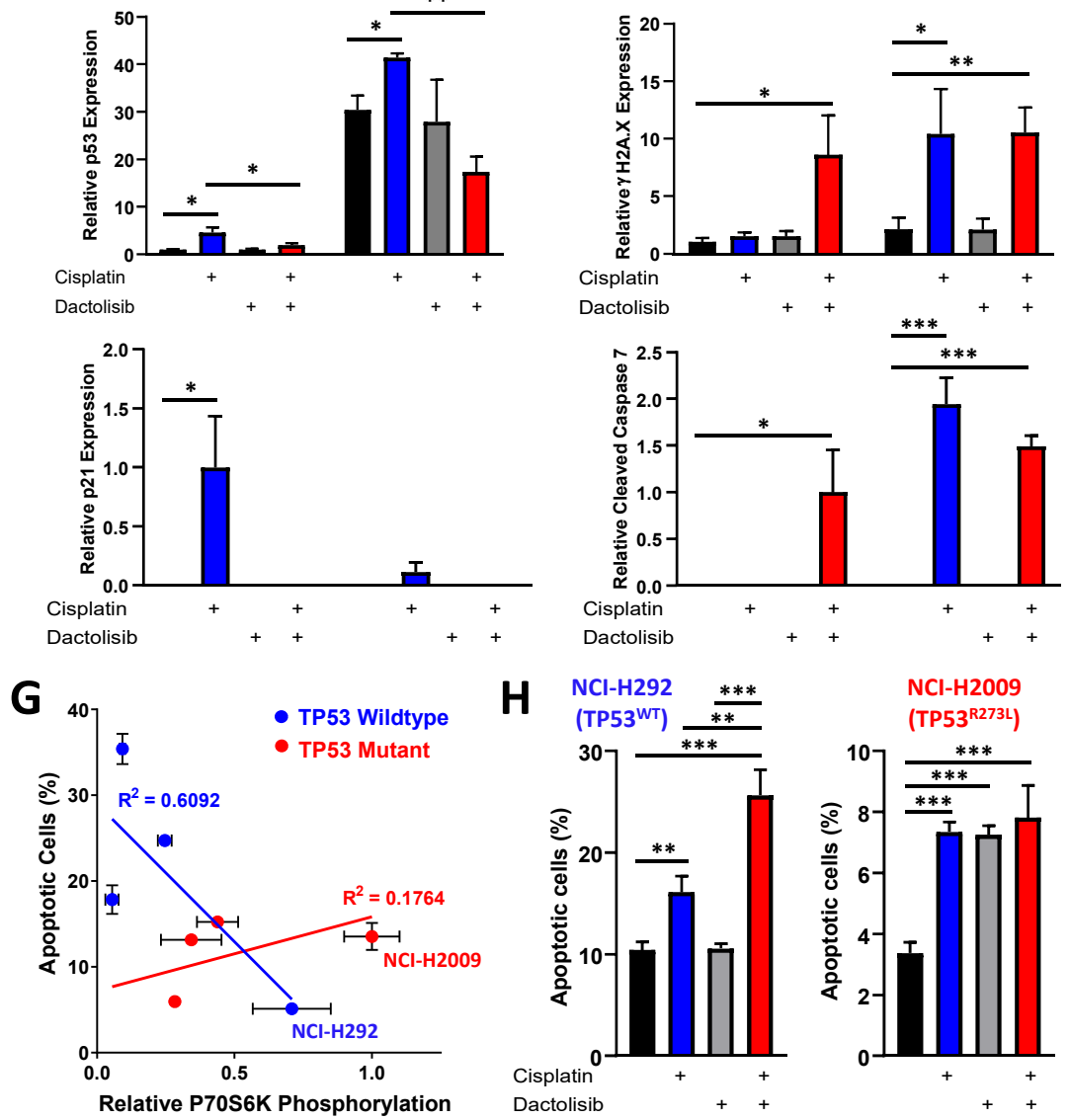

$\mathbf{F}$
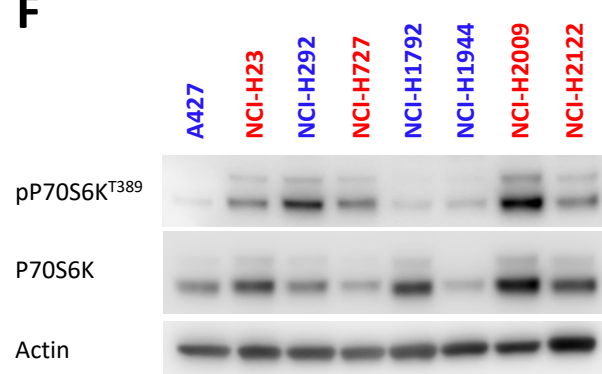

Actin
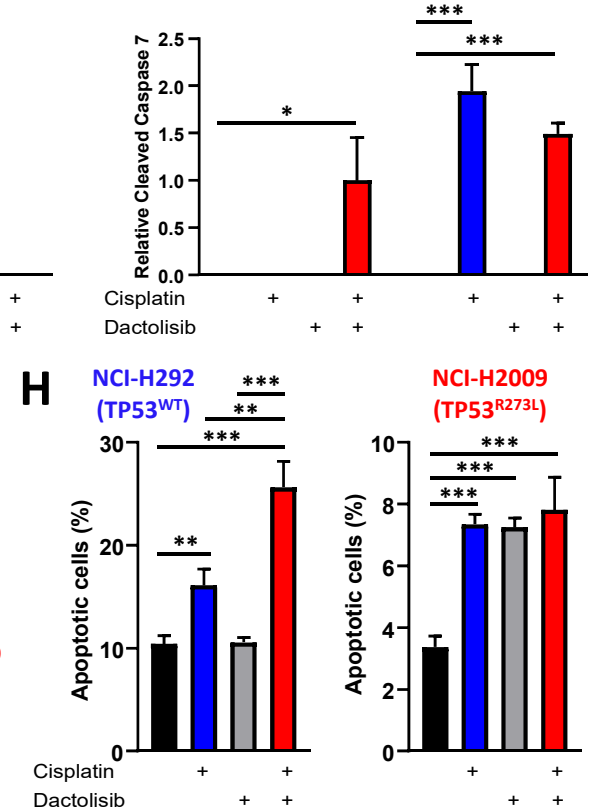


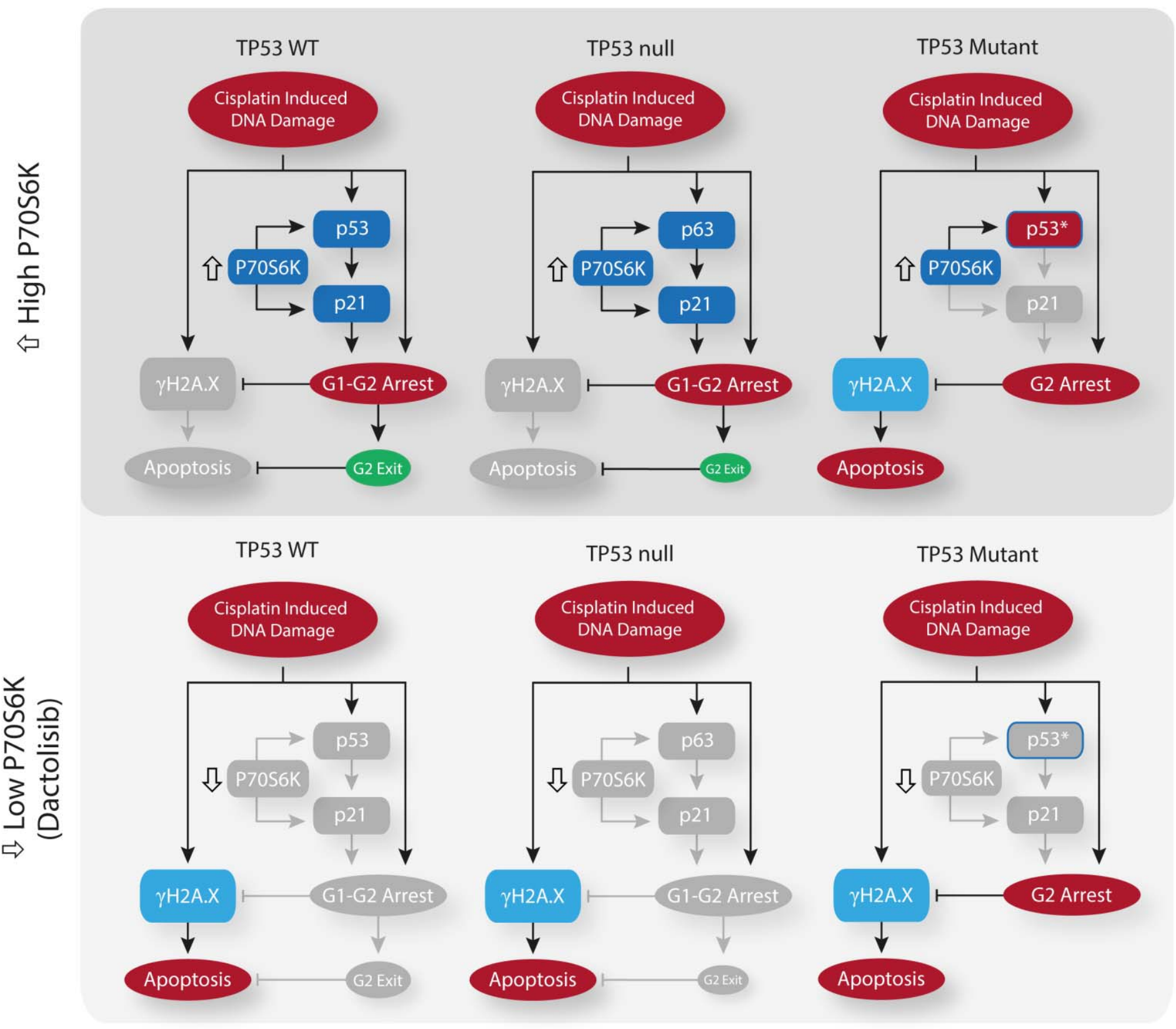

Figure 7: Schematic outlining the effect of cisplatin on cell cycle arrest, DNA damage and apoptosis across the spectrum of TP53 mutation states, and the influence of P70S6K expression levels or inhibition upon these processes. 

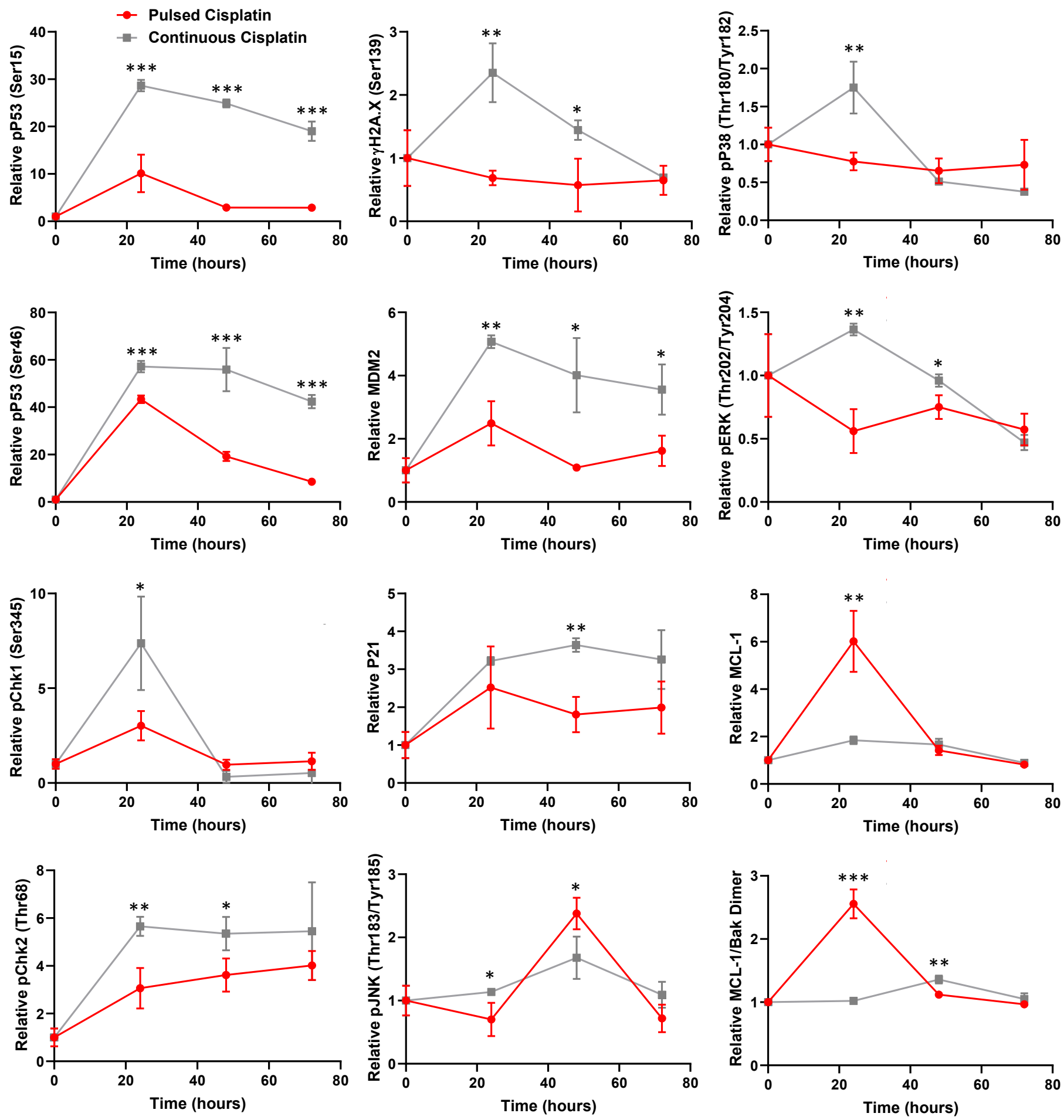

Supplementary Figure 1: Continuous versus pulsed cisplatin treatment of A549 cells. Raw data for the timecourse, multiplex analysis of DNA damage response proteins following continuous cisplatin treatment (grey) or a cisplatin pulse (red) $(5 \mu \mathrm{g} / \mathrm{mL}, 2 \mathrm{~h})$ in A549 cells $\left(\mathrm{n}=3\right.$, mean \pm SD. ${ }^{* * *} \mathrm{p}<0.001,{ }^{* *} \mathrm{p}<0.01, * \mathrm{p}<$ $0.05)$.

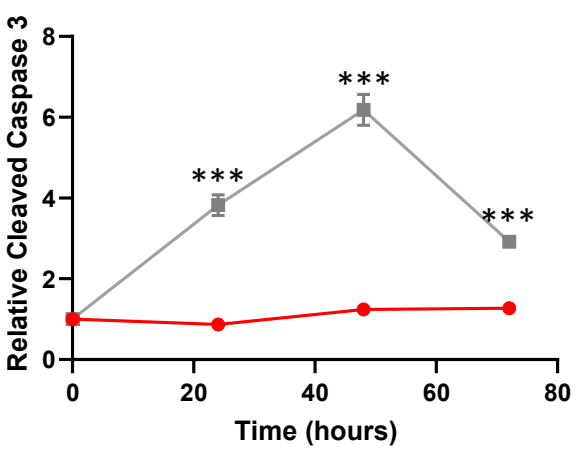




\section{Cisplatin-DNA IF}

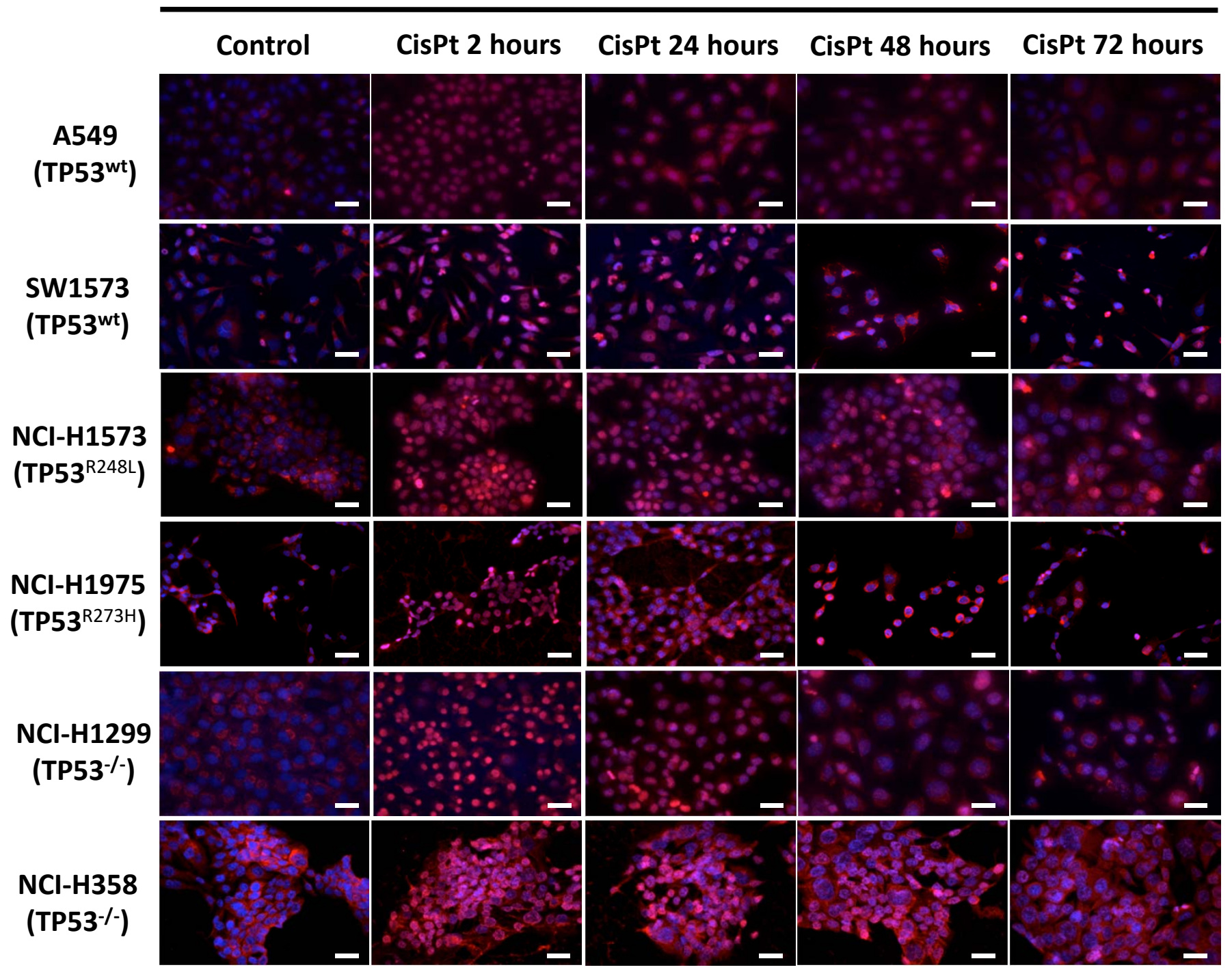

Supplementary Figure 2: Imaging of cisplatin-DNA adducts. Representative images of anticisplatin antibody staining across the cell line panel following a cisplatin pulse (Scale bar: $40 \mu \mathrm{m}$ ). 
Chk1 (Ser345)

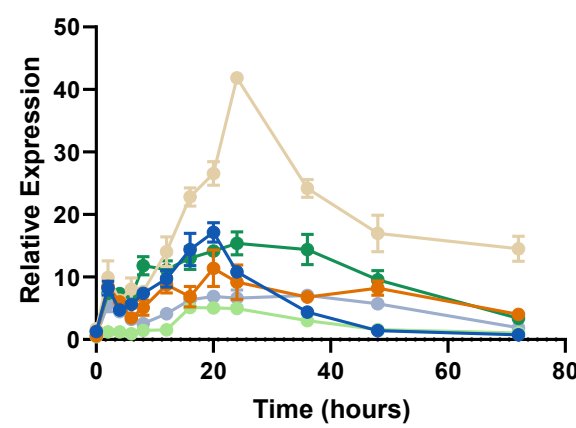

P53 (total)

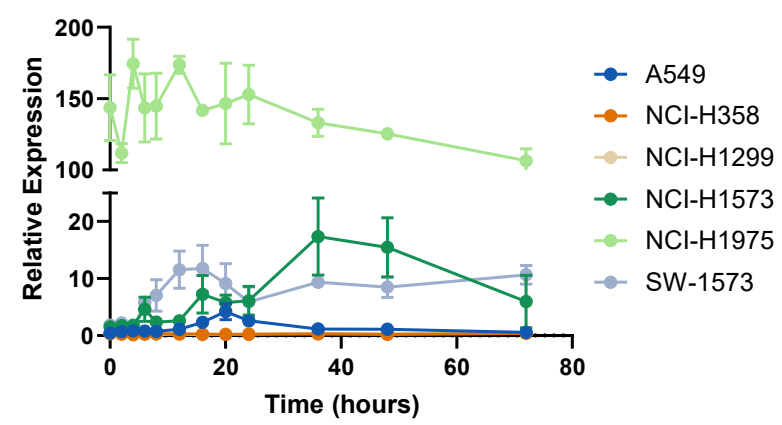

P53 (Ser46)

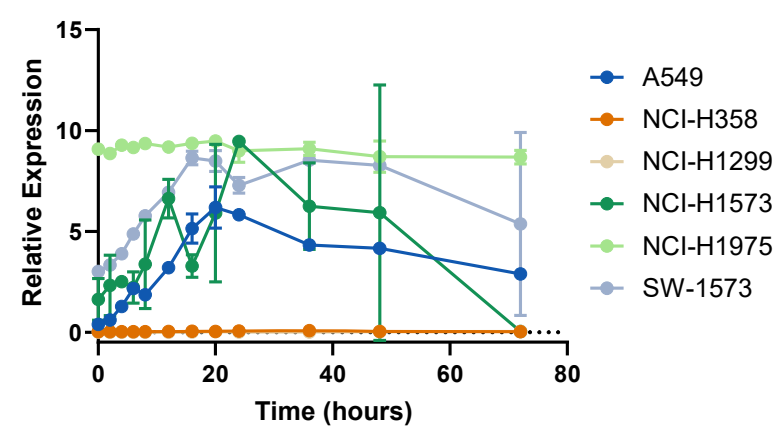

MDM2 (total)

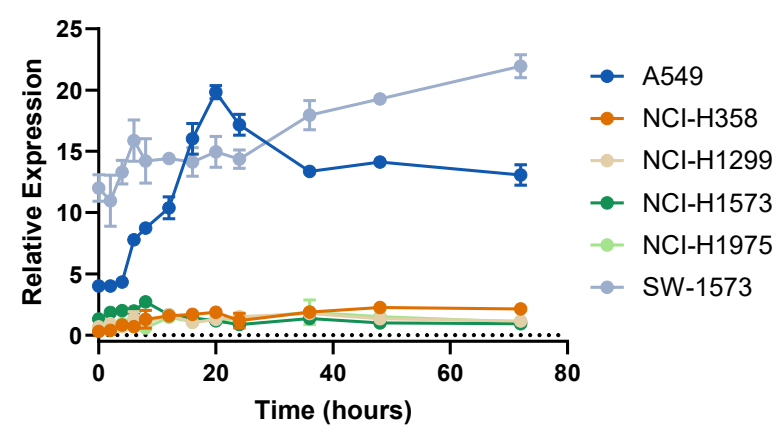

Chk2 (Thr68)

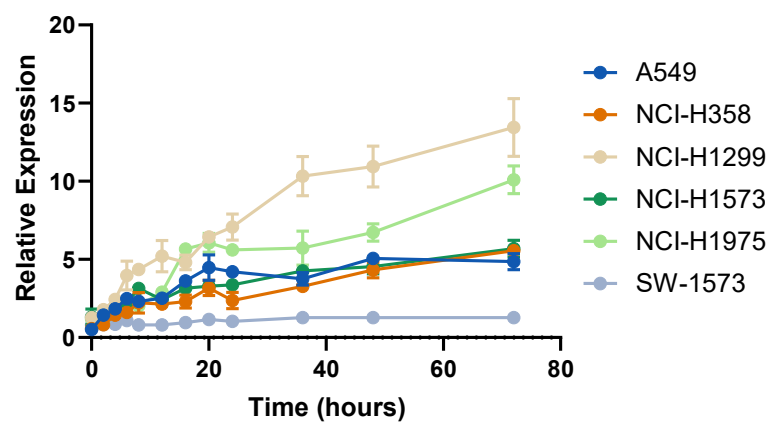

P53 (Ser15)

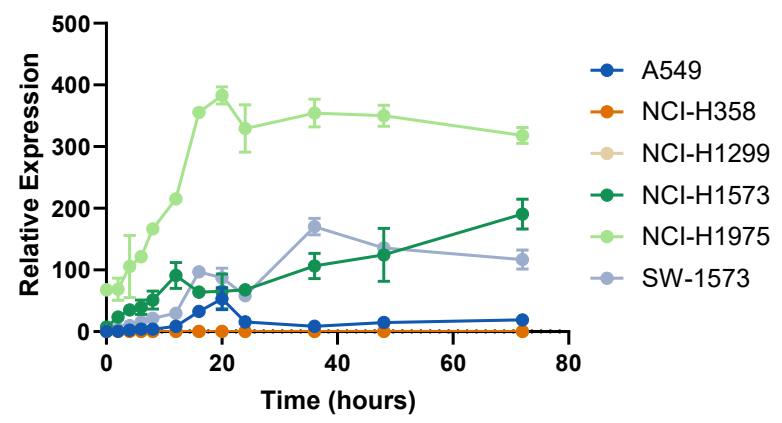

P21 (total)

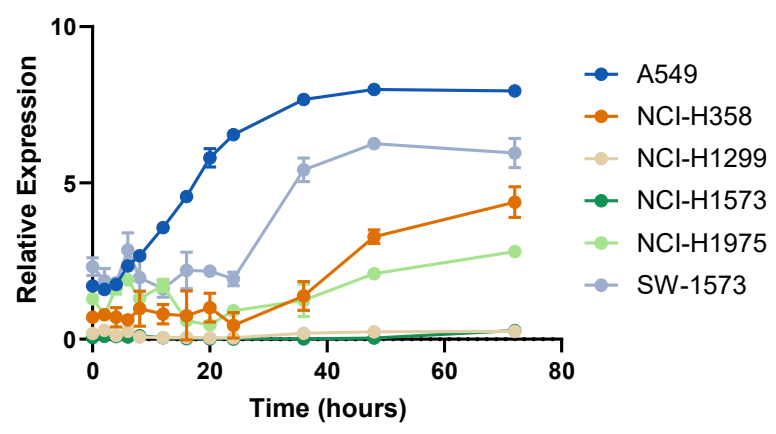

Supplementary Figure 3: p53 pathway dynamics. Raw data for the timecourse, multiplex analysis of DNA damage response proteins following a cisplatin pulse (5 $\mu \mathrm{g} / \mathrm{mL}, 2 \mathrm{~h}$ ) across a panel of cell lines, as indicated $(n=3$, mean $\pm S D)$. 


\section{A Variance Captured in PCA Analysis}

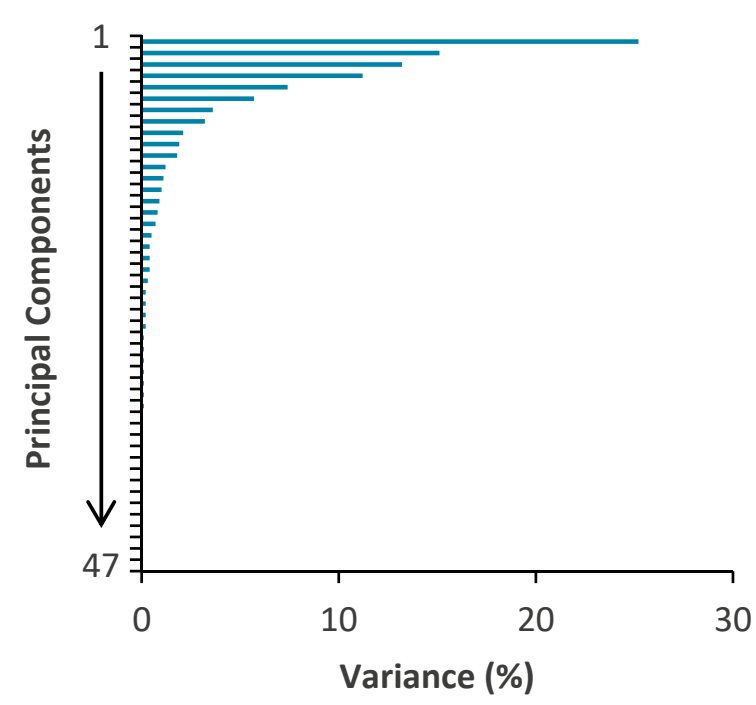

B Live-cell imaging of apoptosis

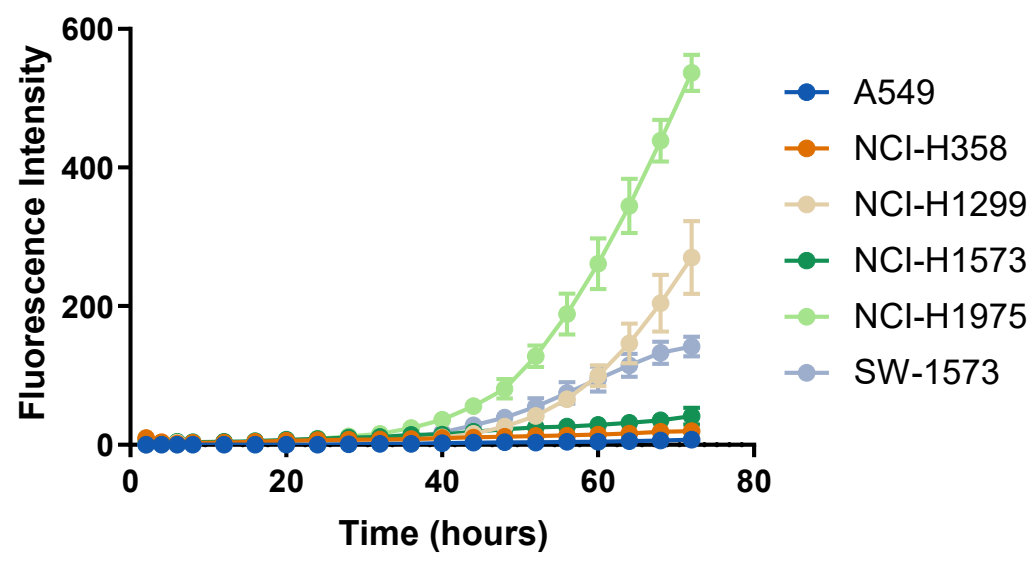

C Apoptosis assay in SW1573 cells

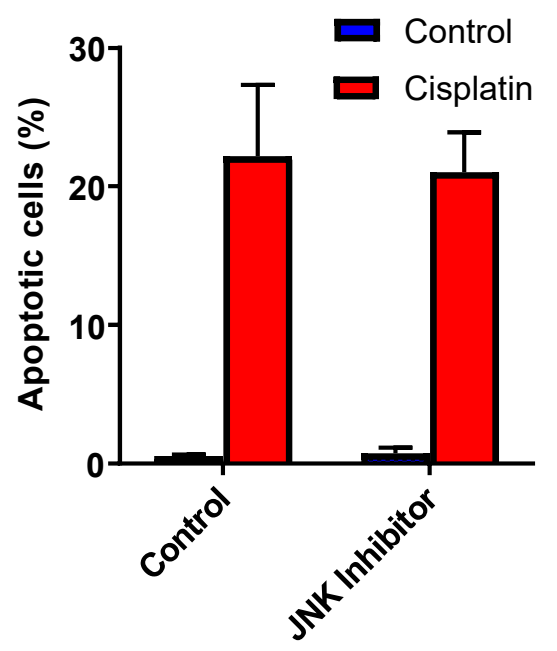

Supplementary Figure 4: (A) The variance captured within each principal component of the principal component analysis (PCA), presented in Figure 2. (B) Live-cell imaging of apoptosis across the cell lines indicated on the Incucyte platform using a fluorescent caspase substrate $(1 \mu \mathrm{M}) \quad(\mathrm{n}=3$, mean $\pm \mathrm{SD})$. (C) Apoptosis measured by propidium iodide staining for the sub-G1 population in SW1573 cells, performed $72 \mathrm{~h}$ following a cisplatin pulse $(5 \mu \mathrm{g} / \mathrm{mL}, 2 \mathrm{~h})$ with the addition of a JNK inhibitor (JNK VIII, $20 \mu \mathrm{M})$ as indicated $(\mathrm{n}=3$, mean $\pm \mathrm{SD})$. 

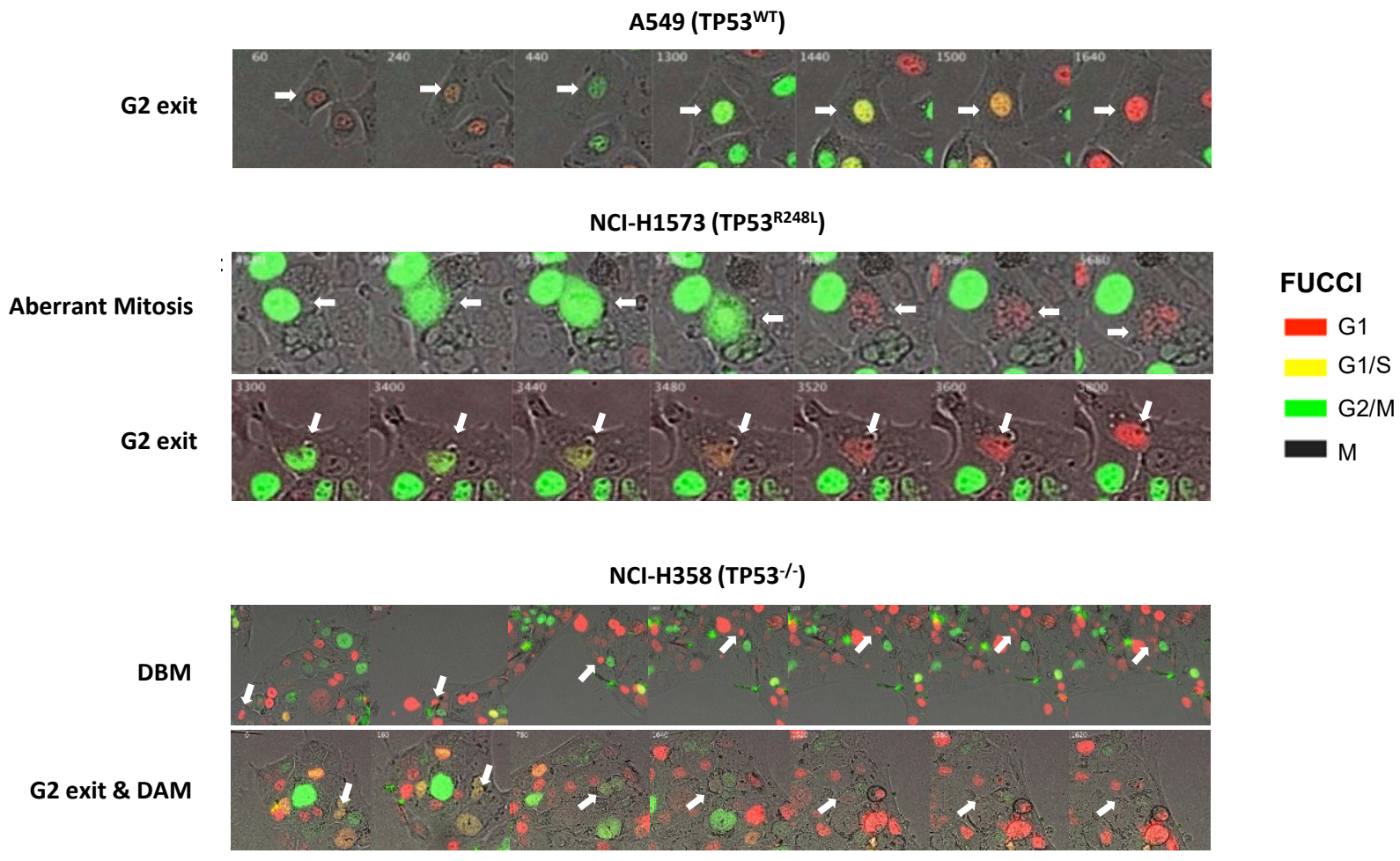

Supplementary Figure 5: Representative images of cells expressing the FUCCI biosensor, undergoing an aberrant mitosis, G2 exit, Death before Mitosis (DBM) and Death after Mitosis (DAM) following a cisplatin pulse $(5 \mu \mathrm{g} / \mathrm{mL}, 2 \mathrm{~h})$. 
Supplementary Table 1: Mutation status of the lung adenocarcinoma cell panel.

\begin{tabular}{lllll} 
Cell line & TP53 & RAS & EGFR & CDKN2A \\
\hline A549 & WT & KRAS G12S & WT & Del (Hom) \\
SW-1573 & WT & KRAS G12C & WT & Del (Hom) \\
NCI-H1573 & R248L (Hom) & KRAS G12A & WT & WT \\
NCI-H1975 & R273H (Hom) & WT & T790M, & WT \\
NCI-H358 & Del (Hom) & KRAS G12C & WT & WT \\
NCI-H1299 & Del (Hom) & NRAS Q61K & WT & WT
\end{tabular}


Supplementary Table 2: Summary of the analytes used for multiplex signalling analysis.

\begin{tabular}{|c|c|}
\hline Pathway & Analytes \\
\hline $\begin{array}{l}\text { DNA Damage } \\
\text { Response }\end{array}$ & $\begin{array}{l}\text { ATR (total), Chk1 (Ser345), Chk2 (Thr68), P53 (total), P53(Ser15), } \\
\text { P53 (Ser46), MDM2 (total), P21 (total), } \gamma \text { H2AX (Ser139), cleaved } \\
\text { PARP }\end{array}$ \\
\hline $\begin{array}{l}\text { AKT/mTOR } \\
\text { Signalling }\end{array}$ & $\begin{array}{l}\text { IRS-1 (Ser636/639), Akt (Ser473), BAD (Ser136), BAD (Ser112), } \\
\text { Bcl-2 (Ser70), GSK-3 } \alpha / \beta \text { (Ser21/9), S6 ribosomal protein } \\
\text { (Ser235/236), PTEN (Ser380), mTOR (Ser2448), P70S6K (Thr389) }\end{array}$ \\
\hline $\begin{array}{l}\text { MAPK } \\
\text { Signalling }\end{array}$ & $\begin{array}{l}\text { MEK1 (Ser217/221), ERK1/2 (Thr202/Tyr204), P90RSK (Ser380), } \\
\text { P38 (Thr180/Tyr182), HSP27 (Ser78), JNK (Thr183/Tyr185), c-Jun } \\
\text { (Ser63), ATF2 (Thr71), STAT1 (Tyr701), STAT3 (Ser727) }\end{array}$ \\
\hline $\begin{array}{l}\text { TGF } \beta \\
\text { Signalling }\end{array}$ & $\begin{array}{l}\text { TGFßRII (total), Smad2 (Ser465/467), Smad3 (Ser423/425), Smad4 } \\
\text { (total) }\end{array}$ \\
\hline $\begin{array}{l}\text { NF-кB } \\
\text { Signalling }\end{array}$ & NF-кB (Ser536), IкB $\alpha(\operatorname{Ser} 32 / 36)$ \\
\hline $\begin{array}{l}\text { Apoptosis } \\
\text { Regulators }\end{array}$ & $\begin{array}{l}\text { BAD (total), Bcl-xL (total), BIM (total), MCL-1 (total), Bcl-xL/BAK } \\
\text { dimer (total), MCL-1/BAK dimer (total), BAX/Bcl-2 dimer (total), } \\
\text { Survivin (total) }\end{array}$ \\
\hline $\begin{array}{l}\text { Apoptosis } \\
\text { Effectors }\end{array}$ & Active Caspase- 8 , Active Caspase- 9 , Active Caspase- 3 \\
\hline
\end{tabular}


Supplementary Table 3: Characteristics of the patient cohort used to generate immunohistochemical data. $\mathrm{CI}=$ confidence interval.

Total Samples

Histology

Stage

Chemotherapy
Adenocarcinoma

Large cell favouring adenocarcinoma

Mucinous adenocarcinoma

IV

IIIA

IIIB

III

IIB

II

Carboplatin/Gemcitabine

Carboplatin/Pemetrexed

Carboplatin/Pemetrexed +/- Pembrolizumab

Carboplatin/Taxol + Bevacizumab

Concurrent Carboplatin/Taxol

Concurrent Cisplatin/Etoposide

Concurrent Carboplatin + Unknown n $\%$

52

$50 \quad 96.2 \%$

$1 \quad 1.9 \%$

$1 \quad 1.9 \%$

$36 \quad 69.3 \%$

$8 \quad 15.4 \%$

$5 \quad 9.6 \%$

$1 \quad 1.9 \%$

$1 \quad 1.9 \%$

$1 \quad 1.9 \%$

$28 \quad 53.8 \%$

$3 \quad 5.8 \%$

$4 \quad 7.7 \%$

$2 \quad 3.8 \%$

$11 \quad 21.2 \%$

$3 \quad 5.8 \%$

$1 \quad 1.9 \%$ 


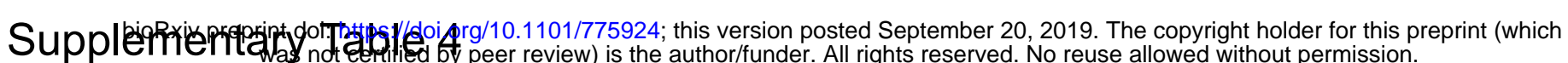

Supplementary Table 4: Mutation status of second lung adenocarcinoma cell panel.

\begin{tabular}{lllll} 
Cell line & TP53 & RAS & EGFR & CDKN2A \\
\hline A-427 & WT & KRAS G12D & WT & Del (Hom) \\
NCI-H2122 & Q236L, C176F & KRAS G12C & WT & WT \\
NCI-H1792 & WT & KRAS G12C & WT & W110* \\
NCI-H1944 & WT & KRAS G13C & WT & Del(Hom) \\
NCI-H2009 & R273L & KRAS G12A & WT & WT \\
NCI-H727 & Q165insYKQ & KRAS G12V & WT & WT \\
NCI-H292 & WT & WT & WT & Del(Hom) \\
NCI-H23 & M264I (Hom) & KRAS G12C & WT & WT
\end{tabular}

